\title{
Aspects of Point-of-Care Diagnostics for Personalized Health Wellness
}

This article was published in the following Dove Press journal:

International Journal of Nanomedicine

\author{
Sandeep Kumar' \\ Monika Nehra' \\ Sakina Khurana' \\ Neeraj Dilbaghi' \\ Vanish Kumar $\mathbb{D}^{2}$ \\ Ajeet Kaushik $\mathbb{D}^{3}$ \\ $\mathrm{Ki}$-Hyun $\mathrm{Kim}^{4}$ \\ 'Department of Bio and Nano \\ Technology, Guru Jambheshwar \\ University of Science and Technology, \\ Hisar, Haryana I2500 I, India; ${ }^{2}$ National \\ Agri-Food Biotechnology Institute \\ (NABI), Mohali, Punjab, India; \\ ${ }^{3}$ NanoBioTech Laboratory, Department \\ of Natural Sciences, Division of Sciences, \\ Art, \& Mathematics, Florida Polytechnic \\ University, Lakeland, FL, 33805-853I, \\ USA; ${ }^{4}$ Department of Civil \& \\ Environmental Engineering, Hanyang \\ University, Seoul 04763, Republic of \\ Korea
}

\begin{abstract}
Advancements in analytical diagnostic systems for point-of-care (POC) application have gained considerable attention because of their rapid operation at the site required to manage severe diseases, even in a personalized manner. The POC diagnostic devices offer easy operation, fast analytical outcome, and affordable cost, which promote their advanced research and versatile adoptability. Keeping advantages in view, considerable efforts are being made to design and develop smart sensing components such as miniaturized transduction, interdigitated electrodes-based sensing chips, selective detection at low level, portable packaging, and sustainable durability to promote POC diagnostics according to the needs of patient care. Such effective diagnostics systems are in demand, which creates the challenge to make them more efficient in every aspect to generate a desired bio-informatic needed for better health access and management. Keeping advantages and scope in view, this mini review focuses on practical scenarios associated with miniaturized analytical diagnostic devices at POC application for targeted disease diagnostics smartly and efficiently. Moreover, advancements in technologies, such as smartphone-based operation, paper-based sensing assays, and lab-on-a-chip (LOC) which made POC more sensitive, informative, and suitable for major infectious disease diagnosis, are the main focus here. Besides, POC diagnostics based on automated patient sample integration with a sensing platform is continuously improving therapeutics interventions against specific infectious disease. This review also discussed challenges associated with state-of-the-art technology along with future research opportunities to design and develop next generation POC diagnostic systems needed to manage infectious diseases in a personalized manner.
\end{abstract}

Keywords: point-of-care devices, infectious diseases, lateral flow strips, microfluidics

\section{Need of Point-of-Care Diagnostics}

Worldwide, long-term economic and social stability of society is highly dependent upon the personnel health. Despite technological advances in past few years, the society is still struggling with adverse health issues in terms of both communicable and non-communicable diseases, especially in developing countries. The limited availability of medical or laboratory testing facilities can cause high mortality rates. The fundamental basis of any treatment procedure is first to identify the disease through reliable and accurate diagnostic tools. The available conventional diagnostic methods are majorly based on immunology, culture and microscopy, and polymerase chain reaction (PCR). These methods have greatly contributed to the diagnosis and monitoring of diseases and are still used as gold standards, but each method has their own benefits and limitations in terms of their functions such as processing speed, cost, and skilled technicians' requirements. For instance,
Correspondence: Sandeep Kumar

Department of Bio and Nano Technology, Guru Jambheshwar University of Science and Technology, Hisar, Haryana 125001

Email ksandeep36@yahoo.com

Ki-Hyun Kim

Department of Civil \& Environmental

Engineering, Hanyang University, 222

Wangsimni-Ro, Seoul 04763, Republic of

Korea

Email kkim6I@hanyang.ac.kr
International Journal of Nanomedicine 2021:16 383-402 
in the case of dengue diagnostics, ELISA cannot identify the serotype, ${ }^{1}$ whereas RT-PCR allows rapid identification of serotype, but its operation requires high proficiency. ${ }^{2}$ Recent outbreaks of infectious diseases (ie, COVID-19, Ebola, and Zika) in remote areas raised concern regarding conventional diseases monitoring strategies. ${ }^{3-5}$ Among several infectious diseases, a few infectious diseases (like AIDS, tuberculosis, hepatitis, etc.) are largely causing illness and death, especially in developing countries, due to lack of modern medical care. In the conventional techniques, a considerable time lag between sample collection to further assessments is a major challenge in front of infectious disease management. In order to accelerate the diagnosis, research efforts have recently focused on development of point-of-care (POC) devices. ${ }^{6-9}$

POC testing for medical diagnosis involves close proximity to patients to enable contemporaneous treatments. Over time, POC devices have gained attention for rapid diagnosis and monitoring various life-threatening or infectious diseases. The early and accurate diagnosis of disease is important in the initiation of early treatment of diseases followed by appropriate modification of treatment steps, if necessary, via facile monitoring. POC devices are efficient diagnostic options to prevent delay in treatment, which is important because delays or inappropriate treatments can lead to high mortality and transmission of infectious agents. ${ }^{10,11}$ In resource-limited areas lacking the facilities of laboratory-based diagnostic tests, POC testing is easy-to-use, and an instrument-independent alternative for its possible use even by the people who lack medical or laboratory knowledge. POC testing can be performed at any place either home or physician's office, ideally offering results within minutes with a simple procedure of analysis.

POC devices must be robust with high specificity, selectivity, short turnaround time, minimal processing steps, and capable of immediate clinical-decision making. The global POC diagnostic market is projected to reach US $\$ 28,379.6$ million by $2026 .{ }^{12}$ The POC testing market can be segmented into different products for infectious disease monitoring, glucose monitoring, cardiometabolic testing, coagulation testing, urinalysis testing, hematology testing, drugs testing, and others. Among all these POC tests, a significant growth in development of infectious disease testing products can be seen due to the growing patient population as well as awareness about POC testing of infectious disease. The fundamental technological advances are broadening the concept of POC systems for real clinical value via integration of microfluidics, development of novel materials, and data analytics. ${ }^{13-17}$

In this article, we discuss the emerging technologies for POC testing that involves the coupling of smartphones with novel sensing approaches such as optical sensors and electrochemical sensors. The available POC tests for major infectious disease detection in humans are also explored and highlighted. This review highlights continued developments in disease diagnosis technology, with an emphasis on diagnostic sensitivity and specificity. We assess the performance of existing POC technologies along with the major research challenges for POC tests on their road to commercialization.

\section{Existing and Emerging Point-of- Care Configurations}

The POC testing can be segmented as dipsticks, lateral flow immunoassays (LFIA), and microfluidics. In particular, the first paper-based dipstick test was reported in 1950s for diabetes, dealing with quantification of glucose in urine via an immunoblotting approach. ${ }^{18}$ In parallel to the development of dipsticks, radioimmunoassays and latex agglutination assays were the forerunners of lateral flow tests. ${ }^{19}$ The principle of LFIA involves the interaction of sample with a labeled antibody that is pre-loaded on a strip of either polymer, nitrocellulose, paper, or others. ${ }^{20}$ Microfluidic diagnostic offers precise control over the rate of flow of samples and reagents through micro-channels, enabling the separation and detection of target analyte. ${ }^{21}$ Along with these sample handling platforms, each POC testing system should possess appropriate sampling methods for different kinds of samples (like interstitial fluid, capillary blood, wound exudate, sweat, tears, urine, or saliva) as well as a particular signal transduction unit with easy readout. These testing platforms are usually integrated with some sensing mechanism such as electrochemical, colorimetric, fluorescent, and spectroscopy, ${ }^{22-24}$ where the target analytes can be proteins, ${ }^{25}$ diseasespecific biomarkers, ${ }^{26}$ and cell count. ${ }^{27}$ Each of these existing POC tests has their pros and cons that lead to requirements of technological advancements in terms of duration of analysis, sensitivity, miniaturization, and cost of the device. In particular, LFIA offer rapid, easy to operate, and cheap POC tests with a long shelf life, avoiding any kind of refrigeration for storage. ${ }^{28}$ However, these are suitable for primary screening only due to several limitations such as sample nature-dependent analysis 
time, mandatory good antibody preparation, restriction on sample volume, and others ${ }^{29-31}$ Moreover, their use is also limited in front of demand of highly quantitative and reproducible results. On the other side, microfluidics POCs offer several benefits over conventional systems in terms of use of less sample volume, low reagent consumption, minor sample handling, faster reaction time, easier automation, and enhanced analytical sensitivity. ${ }^{10,32}$ However, accessibility and scalability are among the major barriers in front of commercialization of microfluidic devices. ${ }^{33}$

In detail, there are different phases of POC tests such as the i) preanalytical phase, dealing with the selection of an appropriate approach for test as well as collection of specimens, ii) analytical phase, dealing with the detection of targeted biological signals and further transformation into measurable signal, and iii) postanalytical phase, concerned with the data analysis and display of results followed by further storage or transmission. ${ }^{34}$ The continuous technological development in POC testing can be characterized in terms of smartphone-based technologies, ${ }^{35}$ paper-based technologies, ${ }^{36}$ and fully automated lap-on-a-chip (LOC)-based platforms. ${ }^{37,38}$ Further, the concept of novel assay format (eg, multiplex PCR and/ or multiplex immunoassay) has become popular for simultaneous detection of different infectious diseases. ${ }^{39}$ In particular, the multiplexed immunoassay based on the principle of dual signal amplification can be utilized for screening of various biomarkers simultaneously in a wide range of clinical samples, eg, urine, oral fluid, etc. ${ }^{40}$ Similarly, in the case of multiplex PCR, the simultaneous detection and amplification of more than one gene target can be achieved in one reaction. ${ }^{41}$ With simultaneous screening of several analytes, POC tests can offer a rapid, low-cost, and reliable quantification.

Laksanasopin et $\mathrm{al}^{42}$ developed a smartphone-based POC diagnostic "dongle" and also carried out its preliminary clinical evaluation for detection of antibodies to human immunodeficiency virus (HIV) and syphilis. The developed dongle powered by $4^{\text {th }}$ generation Apple iPod Touch can replicate all optical, electronic, and mechanical functions of gold standard of laboratory-based ELISA (for HIV diagnosis) and rapid plasma regain (for syphilis diagnosis), offering a specificity of $79-100 \%$ and a sensitivity of $92-100 \%$ within a very short time of 15 minutes. This microfluidic platform can be readily adopted for detection of numerous other pathogens. A smartphone-enabled iHealth Align (The Food and
Drug Administration approved product) is available in the market for blood glucose monitoring. ${ }^{43}$ The other smartphone-based technologies serve as colorimetric readers (for $\mathrm{pH}$ and urine test strips) ${ }^{44}$ and flow cytometer (for optofluidic fluorescent imaging of pathogens in blood/water samples). ${ }^{45}$ The use of imaging components of a smartphone is very novel to develop diagnostic tools for resource-limited areas, ie, development of on-chip imaging of schistosoma eggs in urine causing schistosomiasis (a neglected tropical disease) with 100\% specificity and $79 \%$ sensitivity. $^{46}$

Furthermore, paper-based diagnosis has also emerged as a promising and cost-effective format. Several choices are available for selection of substrate such as paper/polymer, filter paper, nitrocellulose paper, paper/nanomaterials, and chromatography paper based on their properties in terms of surface chemistry, porosity, and optical properties. $^{47}$ The most common example of paper-based lateral flow assays (LFAs) is home pregnancy test strips, which are used to detect the hormone human chorionic gonadotropin (hCG) from urine samples. ${ }^{48}$ This detection concept has been further extended for diagnosis of HIV, ${ }^{49}$ hepatic carcinoma biomarkers (ie, alpha fetoprotein), ${ }^{50}$ and others (like nucleic acid testing). ${ }^{51}$ Majorly, research efforts are focused on sensitivity improvement of paperbased assays via incorporation of enzymes ${ }^{52}$ and nanomaterials. ${ }^{53}$ Moreover, microfluidic paper-based electrochemical devices have also been reported for detection of alcohol, cholesterol, nucleic acids, glucose, and uric acid. $^{54}$ The integration of paper-based assays with a smartphone can offer additional functionality for qualitative analysis of diseases, eg, the possibility of different geometry for fluid and analyte handling (like lateral or vertical flow), tunable surface chemistry with barriers or bridges, physical actuation, allowed external fields, and ease of image capture and analysis.

Further, numerous LOC-based POC devices are available in the market such as the portable Piccolo Xpress ${ }^{\mathrm{TM}}$ for analysis of whole blood chemistry. ${ }^{55}$ In this POC, 14 tests can be accommodated on a single reagent LabDisk for simultaneous monitoring of multiple reactions with rapid results delivery within 12 minutes. The LabDisk platforms have been developed for detection of other analytes as well (ie, biomarkers, nucleic acid, toxins, and pathogens). ${ }^{56}$ Recently, the concept of novel assay formats is paving the way for future POC devices with enhanced sensitivities such as TROVA ${ }^{\mathrm{TM}, 57}$ Perkin Elmer's AlphaLISA $^{\circledR, 58}$ etc. 


\section{Point-of-Care Diagnostics of Major Infectious Diseases}

The advancements achieved in POC techniques are astonishing, allowing them to outperform costly late-stage tools for diagnosis and to facilitate early-stage diagnosis with inexpensive options (refer to Table 1). In this section, we discuss the diverse forms of POC tests developed for human applications in detail.

\section{Point-of-Care Diagnostics of Dengue}

Dengue is a viral disease caused by Aedes species of mosquitoes, mainly female $A$. aegypti. There are four main serotypes of dengue virus: DEN-1, DEN-2, DEN-3, and DEN-4. According to WHO reports, about 390 million dengue infections occur yearly. ${ }^{79}$ The symptoms of dengue infection can be confused with those of other infections such as malaria. However, appropriate biomarkers can be used to identify the different stages of dengue infection. Those stages are the initial febrile stage and the later defervescence stage, which involves the release of target antibodies. Different diagnostic tests (such as ELISA, RTqPCR, and serological methods) are routinely used for dengue detection. The viral isolation technique is the gold standard for detection of dengue infections. POC tests for dengue diagnosis are also commercially available, including the Dengue Fever IgG and IgM Combo device, BIOLINE Dengue Duo NS1 antigen and IgG and IgM Combo device, Panbio Dengue Early Rapid Kit, Panbio Dengue Duo Cassette, and STRIP (refer to Table 1). ${ }^{80,81}$ These antibody-based POC tests are based on qualitative detection of non-structural protein 1 (NS1) in human serum in the case of early dengue infections. However, acute dengue detection, especially in the later phase of infection, is still recommended to prevent false-positive diagnoses.

Paper-based diagnostic devices have been developed for rapid, on-site dengue diagnosis. These detection systems use a simple capillary effect on the flow of a biological sample on paper without the need for any external power sources. With the use of an optical reader, the colorimetric tests can provide quantitative measurements based on a strong correlation between concentration of analyte and corresponding color intensity (refer to Figure 1). ${ }^{82}$ In this case, the optical reader eliminates the subjective interpretation of the test results and offers a semiquantitative or even quantitative readout. The development of hybrid substrates (eg, agarose) can offer appropriate control over fluid flow for the optimal interaction between biomolecules and gold nanoparticle-modified test strips. ${ }^{83}$ An opto-magnetic approach has been reported for real-time detection of dengue infection under both ideal and non-ideal conditions. ${ }^{84}$ The interaction between magnetic nanoparticles and products of loop-mediated isothermal amplification (LAMP) was used to diagnose dengue Serotype 2 synthetic DNA (D2) within 20 minutes of the LAMP reaction for target concentrations above $100 \mathrm{fM}$. In the case of nucleic acid-based diagnostics, the adoption of LAMP reaction over PCR can eliminate the requirement of bulky and expensive thermocyclers along with enhanced sensitivity and specificity of target gene amplification. ${ }^{85}$ The continuous development of nanomaterials has produced extremely sensitive biosensors. The integration of a microfluidic system with nanomaterials and microarray technologies is highly effective in achieving the goal of miniaturized, automated, and portable chips for use with complex microfluidic samples such as cells, nucleic acids, and protein assays.

\section{Point-of-Care Diagnostics of Tuberculosis}

Tuberculosis (TB), an infectious disease, is caused by the bacillus Mycobacterium tuberculosis. According to reports, 10 million people worldwide were found to be infected with TB in 2017, and 1.3 million TB-related deaths occurred. ${ }^{86}$ Delay in effective treatment for TB can cause its transmission, with epidemic potential. There is thus an urgent need to identify biomarkers for detection and differentiation of TB. The situation becomes even more critical when TB occurs in a patient already affected by HIV. The WHO reports that the treatment success rate for multidrug resistant TB during 2017 was $55 \%$ globally. ${ }^{87}$ Currently available diagnostic tests for TB can be classified as i) sputum smear microscopy, ii) culture-based methods, and iii) rapid molecular tests. Sputum smear microscopy is one of the most common tools for TB diagnosis and involves simply checking for the presence of bacteria using a microscope. ${ }^{88}$ It is thus a laboratory-based test that involves the examination of multiple samples. Culture-based methods are the current reference standard for testing the drug susceptibility of bacterial strains, but those tests are both laboratory-based and time consuming (12 weeks). ${ }^{89}$ The Xpert $^{\circledR}$ MTB/RIF assay is a WHOrecommended rapid molecular test. The attractive features of this test are its accuracy and rapid processing, in as little as 2 hours. ${ }^{90}$ Other tests for TB and anti-TB drug resistance include the rapid line probe assay (a test for resistance to rifampicin and isoniazid) and sequencing technologies. However, serological tests, including line 


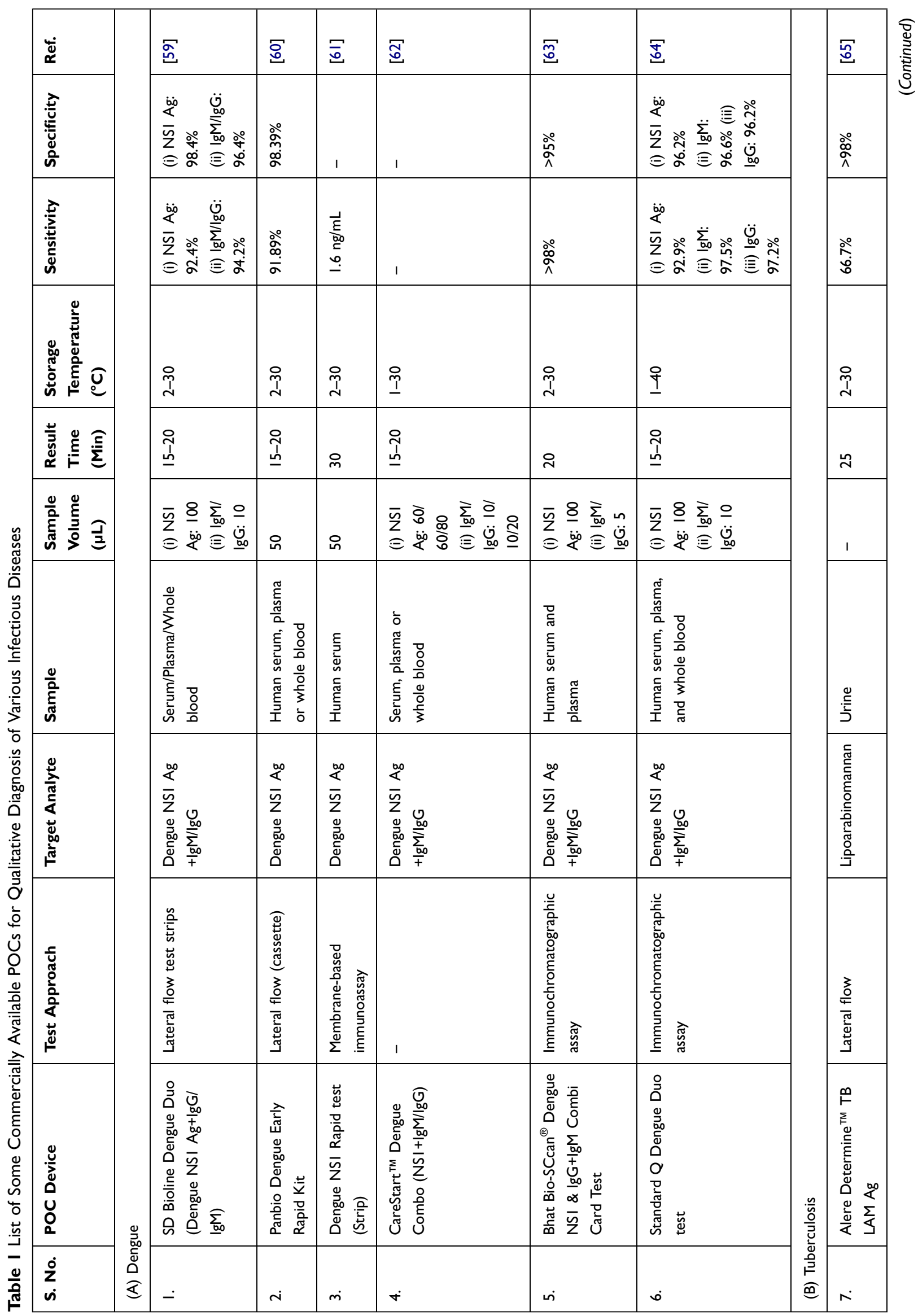




\begin{tabular}{|c|c|c|c|c|c|c|c|c|c|c|c|c|c|}
\hline$\dot{\mathscr{\Phi}}$ & $\begin{array}{l}\text { గi } \\
0 \\
0 \\
0 \\
0\end{array}$ & 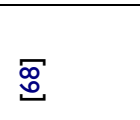 & & $\Xi$ & వ్ర & 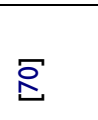 & $\bar{\Sigma}$ & $\mathbb{\Sigma}$ & & $\underline{\Sigma}$ & $\stackrel{\nabla}{ \pm}$ & $\begin{array}{l}\frac{n}{n} \\
\stackrel{ \pm}{ \pm}\end{array}$ & $\stackrel{2}{2}$ \\
\hline 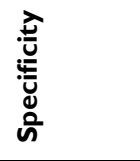 & ڤ̊ & 1 & & $\begin{array}{l}\text { oे } \\
\text { ळ. } \\
\text { o. } \\
i\end{array}$ & 1 & $\begin{array}{l}\stackrel{\circ}{\alpha} \\
\text { ू. }\end{array}$ & $\frac{m}{\dot{s}}$ & $\begin{array}{l}\stackrel{\circ}{\circ} \\
\stackrel{\circ}{\circ}\end{array}$ & & 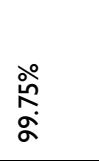 & $\begin{array}{l}\stackrel{\circ}{\circ} \\
\text { ळ. }\end{array}$ & $\begin{array}{l}\stackrel{\circ}{\infty} \\
\text { ळ. }\end{array}$ & 1 \\
\hline 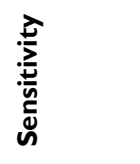 & $\stackrel{\circ}{\stackrel{\infty}{\infty}}$ & 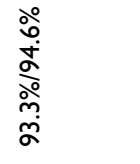 & & ڤ̊ & $\begin{array}{l}\frac{\vec{E}}{\mathrm{~g}} \\
\stackrel{\underline{\underline{0}}}{-}\end{array}$ & $\frac{\stackrel{\circ}{\circ}}{\text { ผू }}$ & $\begin{array}{c}\hat{n} \\
\infty \\
\infty\end{array}$ & $\frac{\stackrel{\circ}{\frac{1}{a}}}{a}$ & & $\frac{\circ}{1}$ & ○े & $\begin{array}{l}\stackrel{\circ}{\circ} \\
\stackrel{\circ}{\alpha}\end{array}$ & 1 \\
\hline 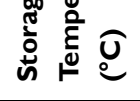 & 1 & $\stackrel{0}{\grave{1}}$ & & ஜे & 1 & 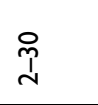 & 1 & 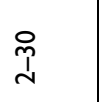 & & 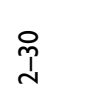 & 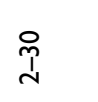 & 1 & 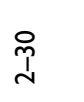 \\
\hline 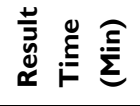 & ஹิ & 흠 & & $\underline{\underline{n}}$ & $\underline{n}$ & $\underline{\underline{n}}$ & $\underline{\underline{n}}$ & 1 & & $\underline{n}$ & 으 & ి & 으 \\
\hline 造 & 1 & $\begin{array}{l}8 \\
0 \\
0 \\
0\end{array}$ & & ㄴ $\begin{array}{ll}\frac{0}{0} & \frac{0}{0} \\
\frac{5}{3} & \circ \\
\end{array}$ & 1 & 1 & I & $\underline{8}$ & & 오 & 1 & 1 & 1 \\
\hline $\begin{array}{l}\frac{0}{0} \\
\text { हूँ } \\
\text { ติ }\end{array}$ & 1 & 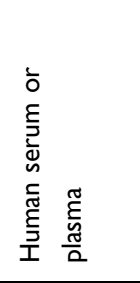 & & 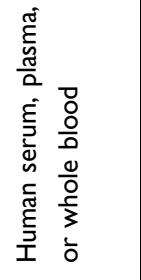 & 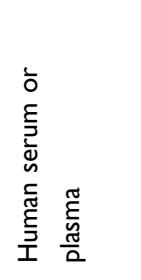 & 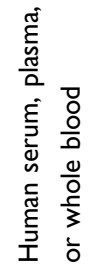 & 1 & 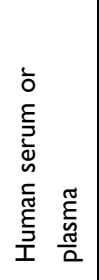 & & 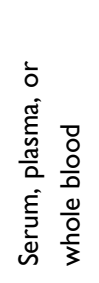 & 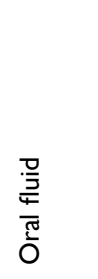 & 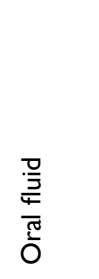 & 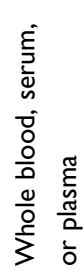 \\
\hline 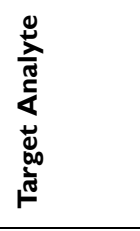 & 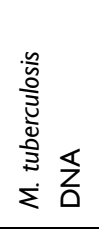 & 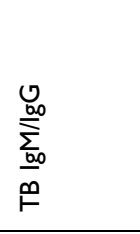 & & $\begin{array}{l}\underset{<}{\infty} \\
\stackrel{\infty}{I}\end{array}$ & $\begin{array}{l}\text { 员 } \\
\text { 蒫 }\end{array}$ & 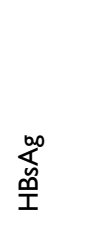 & 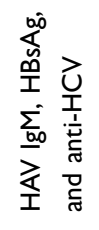 & $\begin{array}{l}\frac{0}{凶} \\
\stackrel{\varphi}{I}\end{array}$ & & 1 & 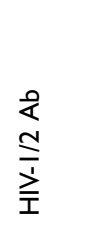 & 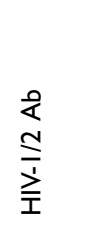 & $\begin{array}{l}\stackrel{0}{\alpha} \\
\stackrel{1}{1} \\
\stackrel{1}{1}\end{array}$ \\
\hline 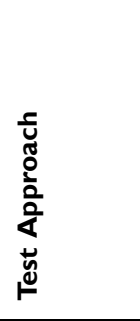 & 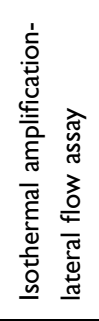 & 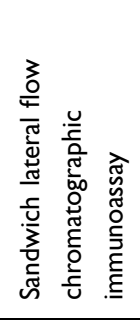 & & 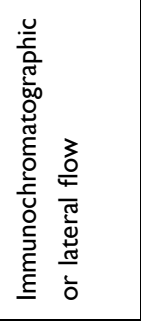 & 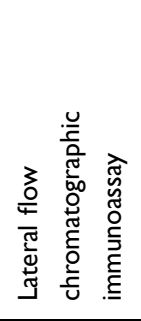 & 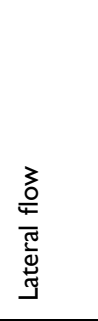 & 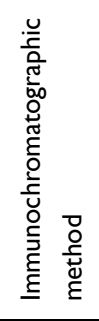 & 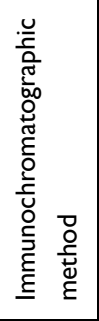 & & 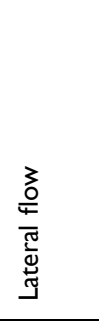 & 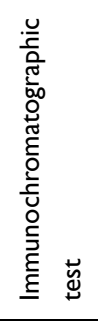 & 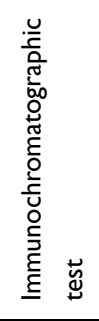 & 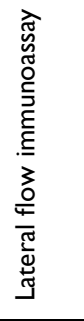 \\
\hline 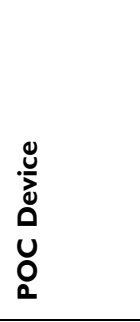 & 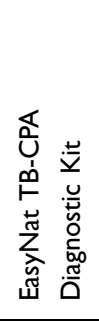 & 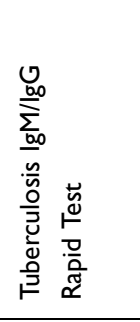 & $\begin{array}{l}\infty \\
\stackrel{n}{\underline{E}} \\
\bar{E}\end{array}$ & 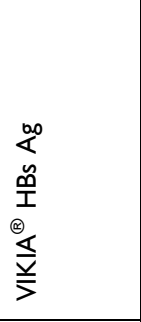 & 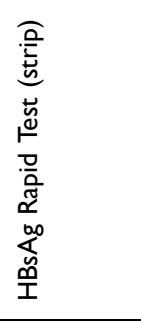 & 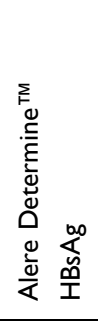 & 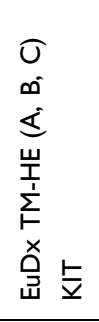 & 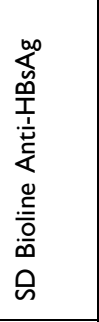 & 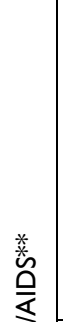 & 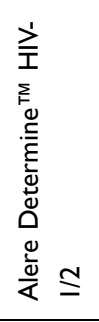 & 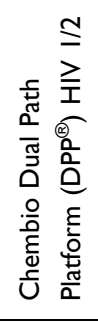 & 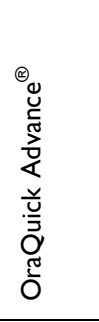 & 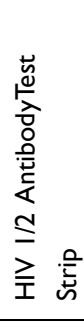 \\
\hline $\begin{array}{l}\dot{z} \\
\text { vi }\end{array}$ & $\infty$ & $\sigma$ & 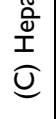 & $\stackrel{\dot{ }}{ }$ & $\dot{=}$ & 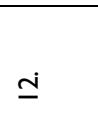 & $\dot{\underline{m}}$ & $\dot{ \pm}$ & $\begin{array}{l}\text { 主 } \\
\text { Q }\end{array}$ & $\underline{\dot{n}}$ & $\stackrel{\dot{ }}{ }$ & $\underline{\sim}$ & $\stackrel{\infty}{\infty}$ \\
\hline
\end{tabular}




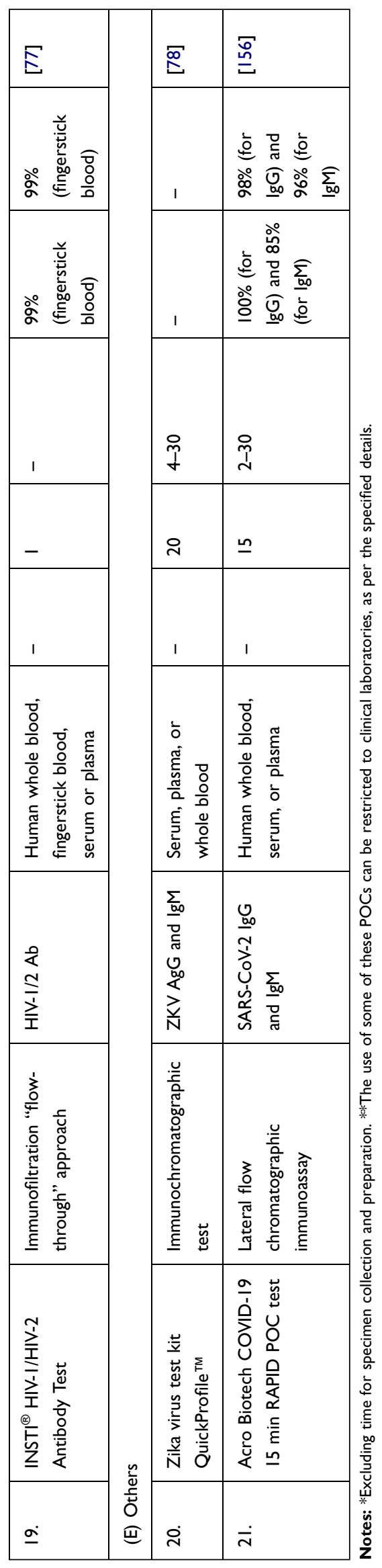

probe assays, are not recommended for diagnosis because of their poor specificity and sensitivity. ${ }^{87}$

In the case of POC tests, the selection of biomarkers should be done carefully keeping in view low cost, easy to operate, and functioning in remote areas with limited laboratory facilities. For TB, the commonly used biomarkers in POC tests are Mtb Ag85, volatile organic compounds from exhaled breath (eg, $\mathrm{H}_{2} \mathrm{O}_{2}, \mathrm{CO}$, or 8-isoprostane), and acute phase proteins (such as C-reactive protein and Alpha-1-acid glycoprotein). ${ }^{91,92}$ Recent trends in POC test development include fluorogenic probes specific for detection of Blac, a hydrolase biomarker expressed by M. tuberculosis. ${ }^{93}$ The CDG-OMe fluorescent probe together with a microfluidic chip can provide enzyme BlaC-based rapid diagnosis of TB with $90 \%$ sensitivity and $73 \%$ specificity over other $\beta$-lactamases. Further improvements are needed to lower the cost of these fluorescent probe-based detection methods. POC devices using a lateral flow urine test-strip assay are commercially available for detection of lipoarabinomannan (LAM) as a TB diagnostic marker (refer to Table 1) ${ }^{94}$ The sensitivity of these TB-LAM detection tools is a major issue in the presence of a concurrent HIV infection. In comparison to commercially-available POC tests for TB, the sensitivity of AlereLAM assay can be improved by using novel Fujifilm SILVAMP TB LAM (FujiLAM) assay (refer to Figure 2). ${ }^{95}$

Beyond the use of antibody-based POC tests, aptamers are becoming an attractive platform because they can offer costeffective synthesis, high stability, ease of modification, and high specificity. ${ }^{96}$ The upcoming trend of integrating microfluidics and nanotechnology is revolutionizing the field of diagnostics with respect to cost, miniaturization, specificity, and sensitivity. The detection of nucleic acids for TB diagnosis could replace the requirement for bacterial isolation or culture. Magnetic nanoprobe-labeled polymeric beads have been fabricated to capture PCR-amplified mycobacterial genes through complementary sequences. ${ }^{97} \mathrm{~A}$ magneto-resistive biosensor offered a low limit of detection (104 cells $/ \mathrm{mL}$ ) for diagnosing Mycobacterium bovis Bacillus Calmette-Guérin. ${ }^{98}$ Using polyaniline-doped carbon nanotubes in an amperometric DNA biosensor offered rapid detection of a specific IS6110 DNA sequence of $M$. tuberculosis in a wide linear range of detection $(1 \mathrm{fM}-10 \mathrm{nM}){ }^{99}$

\section{Point-of-Care Diagnostics of Hepatitis B}

Hepatitis B, a global health problem, is a viral infection of liver caused by the hepatitis B virus (HBV). It can cause both acute and chronic diseases, offering a higher risk of death from liver and cirrhosis cancer. As per the WHO reports, ${ }^{100} 325$ million 


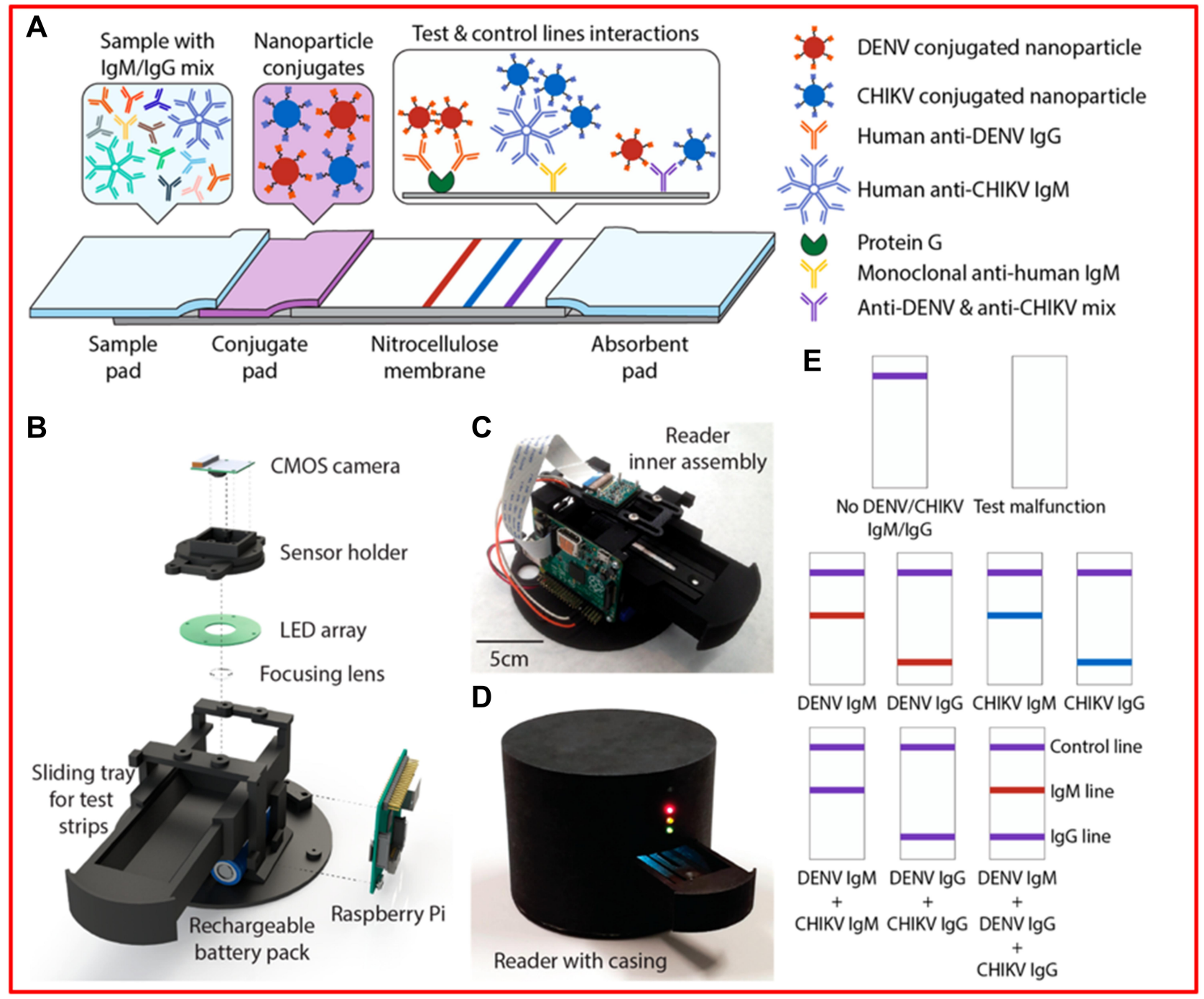

Figure I Rapid diagnostic platform for Dengue and Chikungunya using (A) multiplex lateral flow test strip, (B) optical reader for color detection, (C) structural representation of optical reader, (D) lightproof casing of optical reader, and (E) appearance of test strip corresponding to different diagnostic scenarios.

Note: Reproduced with the permission from Wang R, Ongagna-Yhombi SY, Lu Z, Centeno-Tablante E, Colt S, Cao X, Ren Y, Caardenas WB, Mehta S, Erickson D. Rapid diagnostic platform for colorimetric differential detection of dengue and Chikungunya viral infections. Analytical chemistry. 2019 21;9I(8):54I5-23. Copyright (2019) American Chemical Society. ${ }^{82}$

people are affected with viral hepatitis B and C worldwide, leading to 1.4 million deaths yearly. After tuberculosis, hepatitis B is the second major infectious disease with its 9-times higher cases of infection than HIV. The most common route of this infection is mother-to-infant transmission. ${ }^{101}$ Moreover, the risk of $\mathrm{HBV}$ infection is $43 \%$ higher in diabetic patients in comparison to the non-diabetic population. ${ }^{102}$ The traditional serology and molecular biology-based screening approaches are commonly used for laboratory-based diagnosis of HBV infections. ${ }^{103}$ Three different types of assays have been developed and approved by FDA for HBV diagnosis such as i) HBsAg assay: hepatitis B surface antigen, ii) anti-HBc assay: hepatitis B virus core antigen, and iii) HBV nucleic acid assay: hepatitis B virus. ${ }^{104}$ Further, in comparison to quantification of
HBV DNA using nucleic acid testing, the novel immunoassays (ie, hepatitis B core-related antigen) are more affordable options with a high sensitivity of $96.6 \%$ and a specificity of $85.8 \% .{ }^{105}$ The paper-based analytical devices have also been developed to detect the specific DNA sequences. ${ }^{106}$ However, still improvement is needed to resolve the limitation of complex processing steps for purified DNA samples. Srisomwat et $\mathrm{al}^{107}$ developed a pop-up structured electrochemical paperbased analytical device for label-free detection of HBV DNA. In detail, a pyrrolidinyl peptide nucleic acid (acpcPNA), possessing high affinity and selectivity for target DNA, was covalently immobilized on a working electrode of the device. Here, the electrochemical signal on-off due to respective presence and absence of target HBV DNA was measured with 


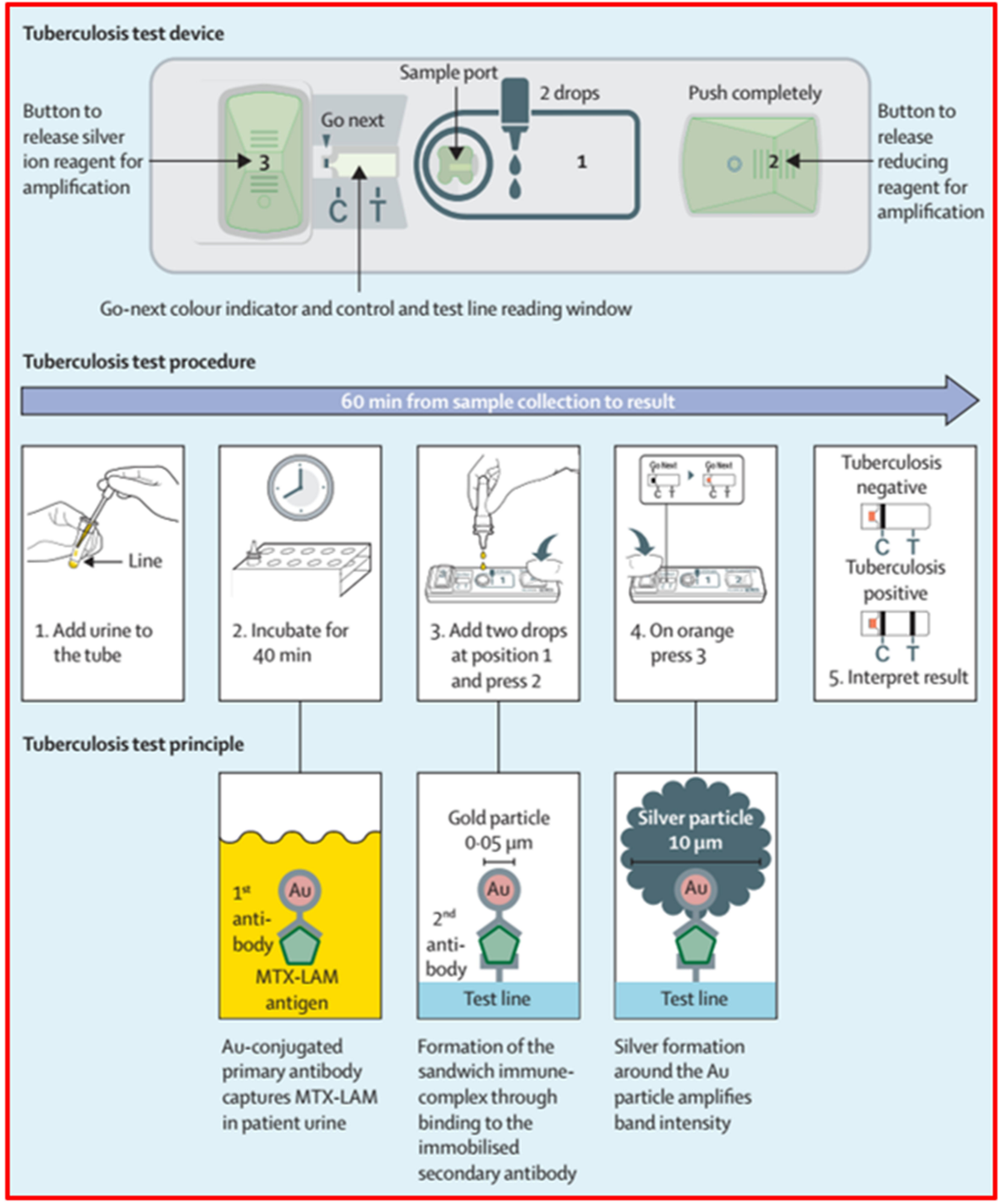

Figure 2 Schematic representation of novel lipoarabinomannan POC device for Tuberculosis diagnosis and its working principle.

Note: Reproduced with the permission form Broger T, Sossen B, du Toit E, Kerkhoff AD, Schutz C, Reipold El, Ward A, Barr DA, Macé A, Trollip A, Burton R. Novel lipoarabinomannan point-of-care tuberculosis test for people with HIV: a diagnostic accuracy study. The Lancet Infectious Diseases. 20I9 Aug I; 19(8):852-6I. Copyright (20I9) Elsevier. ${ }^{95}$ 
differential pulse voltammetry. The pop-up structure offered multi-step operation in a single window as well as ease of sample introduction, minimized exposure of biofluids, and a linear range of $50 \mathrm{pM}-100 \mathrm{nM}$ with a $1.45 \mathrm{pM}$ detection limit.

The development of POC tests for diagnosis of HBV infection is continuous in progress to ensure affordable, specific, sensitive, rapid, and user-friendly alternatives to the society. ${ }^{108-110}$ Some common POC tests are also available in the market, such as Vikia (Biomerieux), ${ }^{111}$ Quick Profile (Lumiquick), ${ }^{112}$ and Determine (Inverness Biomedical Innovations), ${ }^{113}$ etc. (refer to Table 1). Among these POC tests, most of the HBV antigen rapid POC tests (like Vikia and Determine) are based on LFA, whereas Quick Profile is based on a double antibody sandwich immunoassay. The performance of rapid POC tests (ie, EuDx ${ }^{\mathrm{TM}}-\mathrm{HE}$ ) based on immunochromatographic strip assay is comparable to standard references in terms of rapid diagnosis (within 15 minutes) offering high sensitivity of $\sim 95$ with $\sim 99 \%$ specificity for HBsAg. ${ }^{114}$ The recent trends can be seen in combination with integrated multi-diseases oral or blood-based assays for combined testing of $\mathrm{HBV}$, hepatitis $\mathrm{C}(\mathrm{HCV})$, and HIV. ${ }^{115}$ These co-infections (like HIV-HBV and HIV-HCV) have overlapped epidemics. The multiplex POC tests are also available in the market, such as Chembio, OraSure, and MedMira rapid antibody tests with good performance characteristics. ${ }^{116}$

\section{Point-of-Care Diagnostics of HIVIAIDS POC}

Acquired immune deficiency syndrome (AIDS) disease is caused by HIV that directly disturbs the human immune system. The progress made in the science and prevention of HIV infections has motivated many nations to implement integrated health systems to meet HIV prevention and therapeutic goals. ${ }^{117}$ The treatment of HIV infection is a major challenge because of the unavailability of effective vaccines, though several potential vaccines are in various stages of clinical trials. The World Health Organization (WHO) reports that nearly 32 million people died of HIVrelated causes in 2018 and approximately 37.9 million people were living with HIV at the end of 2018. ${ }^{157}$ That report also estimated that only $70 \%$ of people infected with HIV virus knew their status, with the other $30 \%$ unaware due to inaccessibility of diagnostic services. In most new infection cases, people unaware of their HIV status are responsible for its transmission. ${ }^{118}$ At the early stage of infection, it is quite difficult to distinguish the generic symptoms of HIV infection from those caused by common cold or fever.

The POC devices for AIDS detection should be highly sensitive and specific because false negative or positive results could harm the public health. Several potential biomarkers have been identified for HIV diagnosis, eg, peptoid HIV-DxP -1 , viral RNA, and p24 antigens. ${ }^{119,120}$ The Food and Drug Administration (FDA), United States approved highly specific and sensitive POC tests for HIV. ${ }^{121,122}$ Some reported POC tests are the Xpert HIV-1 Qual (nucleic acid-based test for proviral DNA and RNA), Abbott RealTime HIV-1 assay (nucleic acid-based test for HIV-1 RNA), Dual Path Platform $\left(D^{\circledR} P^{\circledR}\right.$ ) HIV $1 / 2$ Screen Assay Oral Test (detection of antibodies to HIV1/2 in oral fluid), and DPP ${ }^{\circledR}$ HIV-HCV Screen Assay Blood Test (detection of antibodies to HIV1/2 in all blood matrices) (refer to Table 1). Among them, the Abbott RealTime HIV-1 assay and Xpert HIV-1 Qual test are nucleic acid-based rapid tests to diagnose HIV-1 infection. ${ }^{123}$ The Xpert HIV-1 Qual test uses the principle of quantitative reverse transcription-PCR (RT-PCR), and its performance is very promising, offering rapid diagnosis with minimal sample-volume requirements. $^{124}$ The Aptima HIV-1 Quant Dx is a dualfunction, fully automated assay used for both diagnosis and monitoring of HIV-1 RNA in plasma. ${ }^{125}$ Another commercially available POC for quantitative detection of HIV-1 RNA in human plasma is rapid assay-based NucliSens v2.0, although it is somewhat complex in terms of handling. Compared with the NucliSens assay, the Xpert and Aptima assays were much more efficient for multiple HIV-1 subtypes and viral loads. ${ }^{126}$ The INSTI ${ }^{\mathrm{TM}}$ HIV-1/HIV-2 Antibody Test is a rapid in vitro test approved by the FDA to test for HIV-1/ HIV-2 using blood and plasma. ${ }^{127}$ As a rapid oral test for HIV, OraQuick offers high sensitivity (93\%) and specificity $(99 \%){ }^{128}$

An electrochemical method based on electrochemical impedance spectroscopy (EIS) has been reported for rapid assessment of HIV infection on using substance of abuse and specific targeted therapeutic drugs. ${ }^{129}$ The cocaine (Coc), as a substance of abuse, tenofovir (Tef), as an anti-HIV drug, and rimcazole (RA), as a Coc antagonist, are selected for this research as model agents. To design an in-vitro cell line model, a cultureware chip (CC) containing interdigitated electrodes of gold (IDE-Au) was used to grow primary human astrocytes (HA) for HIV-infection followed by Coc exposure and treatments with specific drug. The EIS was performed on each step and results confirmed that HIVinfection, Coc exposure, and therapeutic mechanism of drug affected electro-physiology of HA which is detected as 
a foundation of charge transfer resistance (Rct). The presented method successfully detected a Coc impairment procedure and therapeutic action of selected drugs in the HIVinfected cell line. This method has the ability to be used as an analytical diagnostic tool at clinical level which holds potential for fast and timely diagnosis of HIV-infection in a patient to manage HIV diseases, refer to Figure $3 .{ }^{130}$

Further, surface-enhanced Raman scattering (SERS) has been reported to detect target DNA using a plasmonic nanoprobe that behaves as a molecular sentinel. ${ }^{131}$ The probe comprises metallic nanoparticles and a DNA hairpin probe sequence tagged with Raman label for specific and selective detection of the HIV gene. If the target gene is not present in the sample, the Raman label in proximity to the metallic nanoparticle produces an intense SERS effect upon laser excitation. However, the stem-loop configuration gets disrupted upon hybridization of complementary target DNA with a nanoprobe that causes the physical separation of the Raman label from the nanoparticle, resulting in quenching of the SERS signal. The SERS-based LFA can overcome the limitations of conventional LFAs by significantly enhancing the sensitivity (1,000-times) and detection limit $(0.24 \mathrm{pg} / \mathrm{mL})$ for HIV-1 DNA marker detection. ${ }^{132} \mathrm{HIV}$ infections can also be detected by optical detection systems based on the mechanism of surface plasmon resonance (SPR). In comparison to conventional bulky SPR-based sensors, portable SPR sensors have been developed comprising a LED light source, a reflecting mirror, and a gold-coated SPR surface where the target analyte can be detected on the basis of changes in the angle of incidence. ${ }^{133}$ Moreover, these biosensors can be developed using optical microfibers, replacing the reflecting mirror by a fiber core. ${ }^{134}$ SPR biosensors are highly promising for rapid diagnosis of HIV infections, with high sensitivity in a $1 \mathrm{pM}$ to $150 \mathrm{nM}$ linear range and a detection limit of $48 \mathrm{fM} .^{135}$

Micro- and nanotechnology offer various opportunities in HIV diagnosis based on CD4+ T cell counts and HIVviral load measurements. ${ }^{136}$ The major advancements in detection techniques include nanoplasmonic resonance detection $^{137}$ and nanostructured photonic crystals ${ }^{138}$ that can detect viral loads of 100 copies/mL. Furthermore,

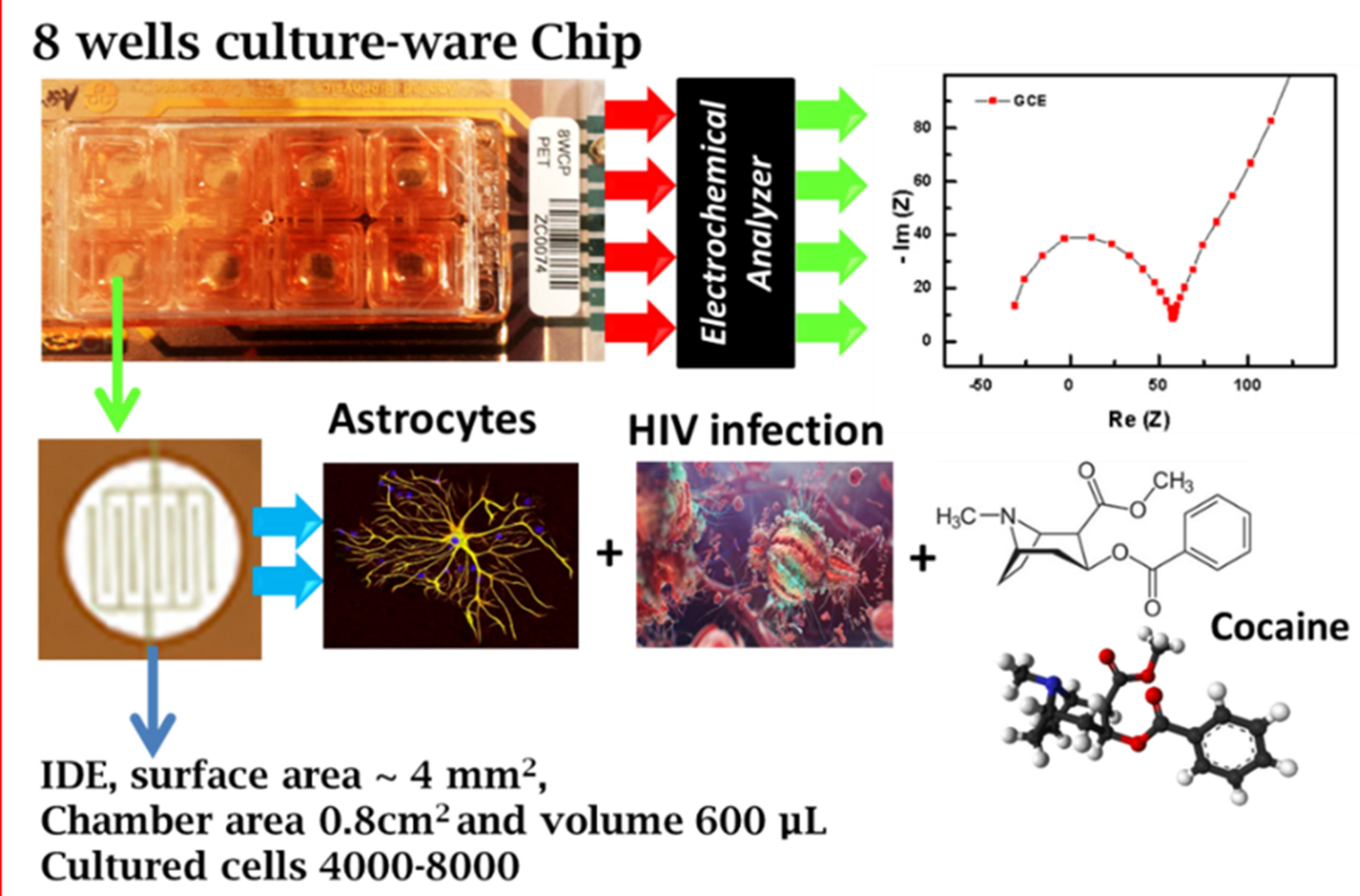

Figure 3 Interdigitated electrodes cultured with Astrocytes and infected by HIV in the presence of cocaine to understand the electrochemical assessment of cell physiology. Note: Reproduced with the permission from Kaushik A, Vabbina PK, Atluri V, Shah P, Vashist A, Jayant RD, Yandart A, Nair M. Electrochemical monitoring-on-chip (E-MoC) of HIV-infection in presence of cocaine and therapeutics. Biosensors and Bioelectronics. 2016 86:426-31. Copyright (2016) Elsevier. ${ }^{130}$ 


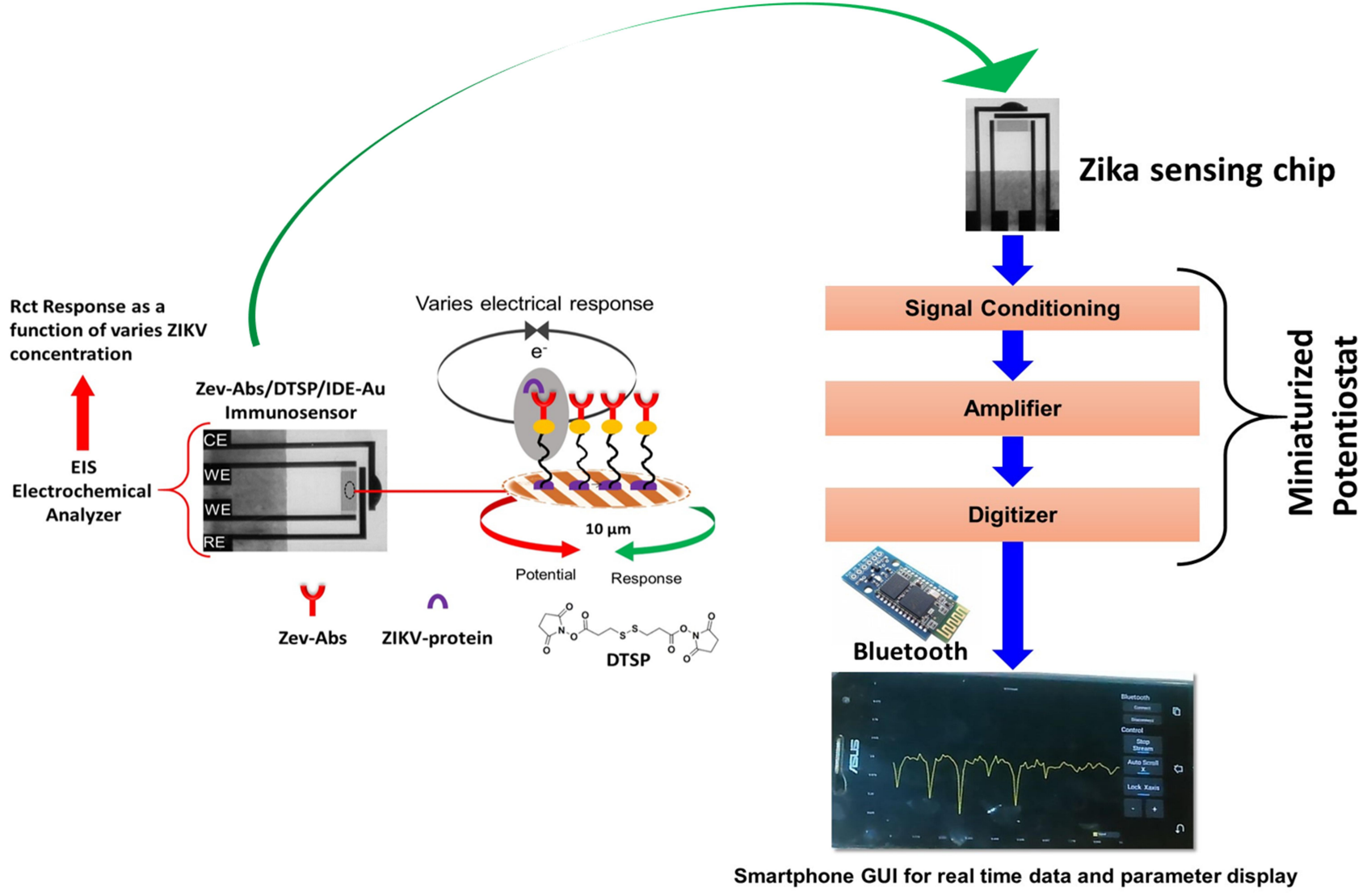

Figure 4 Illustration of an interdigitated electrodes based immunosensor for the detection of ZIKA protein at (PM), to perform POC diagnostics, this sensing chip is projected to be operated by a miniaturized analyzer and data analysis using internet of medical things.

Note: Reproduced with the permission from Kaushik A, Yndart A, Kumar S, Jayant RD, Vashist A, Brown AN, Li CZ, Nair M. A sensitive electrochemical immunosensor for labelfree detection of Zika-virus protein. Scientific reports. 2018 8: 97000. Copyright (2018) Scientific Reports under Creative Commons Attribution 4.0 International License. ${ }^{143}$

development of an immunoassay based on europiumdoped silica nanoparticles enabled the detection of HIV-1 p24 antigen in the femtogram range $(0.02-500 \mathrm{pg} / \mathrm{mL}) .{ }^{139}$ These techniques are very advantageous compared with complicated nucleic acid testing because they can be easily transferred to the LOC platform. Moreover, these techniques can be developed further to detect other antigens and will be especially useful in resource-limited areas.

\section{Point-of-Care Diagnostics of Major Viral Infectious Diseases}

Moreover, POC diagnostics are of significant importance for public health emergency in the case of several other viral infections, eg, infections by Zika virus (ZIKA), Ebola virus, and Covid-19. In particular, the ZIKV (as an infectious disease-causing agent) spreads in humans via mosquitoes (ie, Aedes aegypti and Aedes albopictus). This infection can be further transmited via several ways, eg, through blood transfusion, mother-to-child, bone marrow transplants, and sexual transmission. It results in life-threatening pathogenesis and further progression of disease. However, the diagnostic tools to monitor and control this infection are very limited so far. Different conventional techniques have been reported for diagnosis of ZIKV infection, including antibody methods, reverse transcriptase (RT)-PCR, and viral culture-based approaches. $^{140}$

The integration of immunosensing platforms with microelectronics can lead to POC testing platforms for rapid $(<40$ minutes) and on-site sensing of the ZIKV. ${ }^{141}$ The modification of microelectrodes with various nanostructures (like selfassembled monolayers, surface-charged metal/metal oxide nanoparticles, hybrid nanocomposites, functionalized polymers, and other nanostructured thin films) can lead to high loading of specific antibodies for detection of ZIKV proteins up to picomolar concentrations (Figure 4). ${ }^{142,143}$ Pardee et al $^{144}$ fabricated a low-cost, portable, cell-free, and paper-based diagnostic platform for ZIKV RNA genome detection (up to femtomolar concentrations). The coupling of this paper-based biosensor with clustered regularly interspaced short 


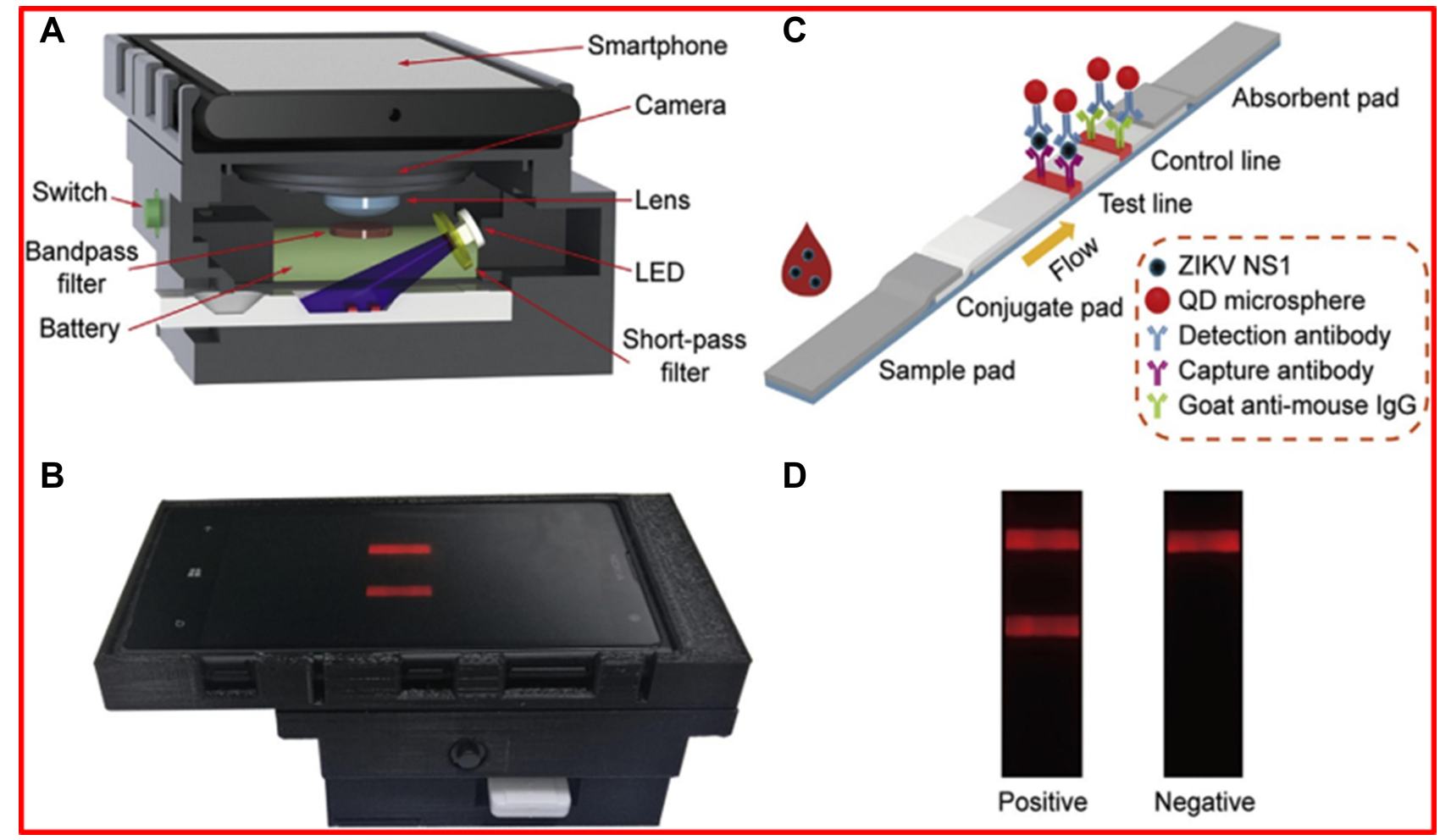

Figure 5 Design and applicability of smartphone-based fluorescent lateral flow immunoassay (LFIA) platform: (A) 3D schematic of internal structure of the device, (B) image of fluorescent LFIA reader, (C) schematic representation of ZIKV NSI detection using fluorescent LFIA, and (D) images of test strips in the absence (right) and presence (left) of ZIKV NSI.

Note: Reproduced with the permission from Rong Z, Wang Q, Sun N, Jia X, Wang K, Xiao R, Wang S. Smartphone-based fluorescent lateral flow immunoassay platform for highly sensitive point-of-care detection of Zika virus nonstructural protein I. Analytica chimica acta. 2019 1055:140-7. Copyright (2019) Elsevier. ${ }^{146}$

palindromic repeats-associated protein-9 nuclease (CRISPRCas9) offered discrimination between viral strains at single base resolution. Further, Song et al ${ }^{145}$ reported implementation of reverse transcription LAMP (RT-LAMP) in a POC disposable cassette for rapid diagnosis of ZIKV. In this case, leuco crystal violet dye was used to detect the amplification products by eye, eliminating the need of any instrumentation for visualization. A low-cost and portable smartphone-based fluorescent LFIA platform reported by Rong et al ${ }^{146}$ offered rapid quantitative detection (within 20 minutes) of ZIKV nonstructural protein $1(\mathrm{NS} 1)$ with a detection limit of 0.045 ng $\mathrm{mL}^{-1}$ and $0.15 \mathrm{ng} \mathrm{mL}^{-1}$ in buffer and serum sample, respectively (refer to Figure 5). Further, the integration of microfluidic assay with a smartphone has offered a major breakthrough in rapid detection ( $\sim 10$ minutes) of ZIKV infection with a detection limit of $62.5 \mathrm{ng} \mathrm{mL}^{-1} .147$

Another viral infection due to Ebola virus (EBOV) (mainly Zaire strain-related) was declared as a deadly persistent epidemic (after the 2014 West African outbreak) due to a lack of rapid diagnosis, detection, and also therapeutics. This EBOV belongs to the family of Filoviridae. EBOV spreads in humans via close contact with organs, secretions, blood, and other body fluids of infected animals, eg, fruit bats, as natural EBOV hosts. Different laboratory diagnostic tools have been developed for EBOV, such as PCR (target: viral nucleic acid), ELISA (target: virus-specific antibodies), antigen ELISA (target: viral antigen), immunohistochemistry (target: viral antigen), indirect immunofluorescence assay (target: virus-specific antibodies), and biosensors (target: virus). ${ }^{148}$ Ciftci et al ${ }^{149}$ reported a padlock probe (PLP)-based rolling circle amplification (RCA) approach for EBOV detection. The enrichment of RCA products on a pump-free microfluidic chip offered good sensitivity, selectivity, and multiplexability for simultaneous detection of Ebola, Dengue, and Zika. Further, Qin et al ${ }^{150}$ reported an automated POC system EBOV RNA detection using RNA-guided RNA endonuclease $\mathrm{Cas}_{13} \mathrm{a}$. This fully solution-based diagnostic approach offered rapid detection (within 5 minutes) with a detection limit of $20 \mathrm{pfu} \mathrm{mL}^{-1}$. Makiala et $\mathrm{al}^{151}$ conducted a clinical evaluation of immunochromatography-based kits (ie, QuickNavi ${ }^{\mathrm{TM}}$-Ebola). On comparing with WHO-approved GeneXert-confirmed cases, QuickNavi $^{\mathrm{TM}}$-Ebola offered a good sensitivity of $85 \%$ and an excellent specificity of $99.8 \%$ for POC diagnosis of EBOV. A POC test comprising a smartphone reader with 


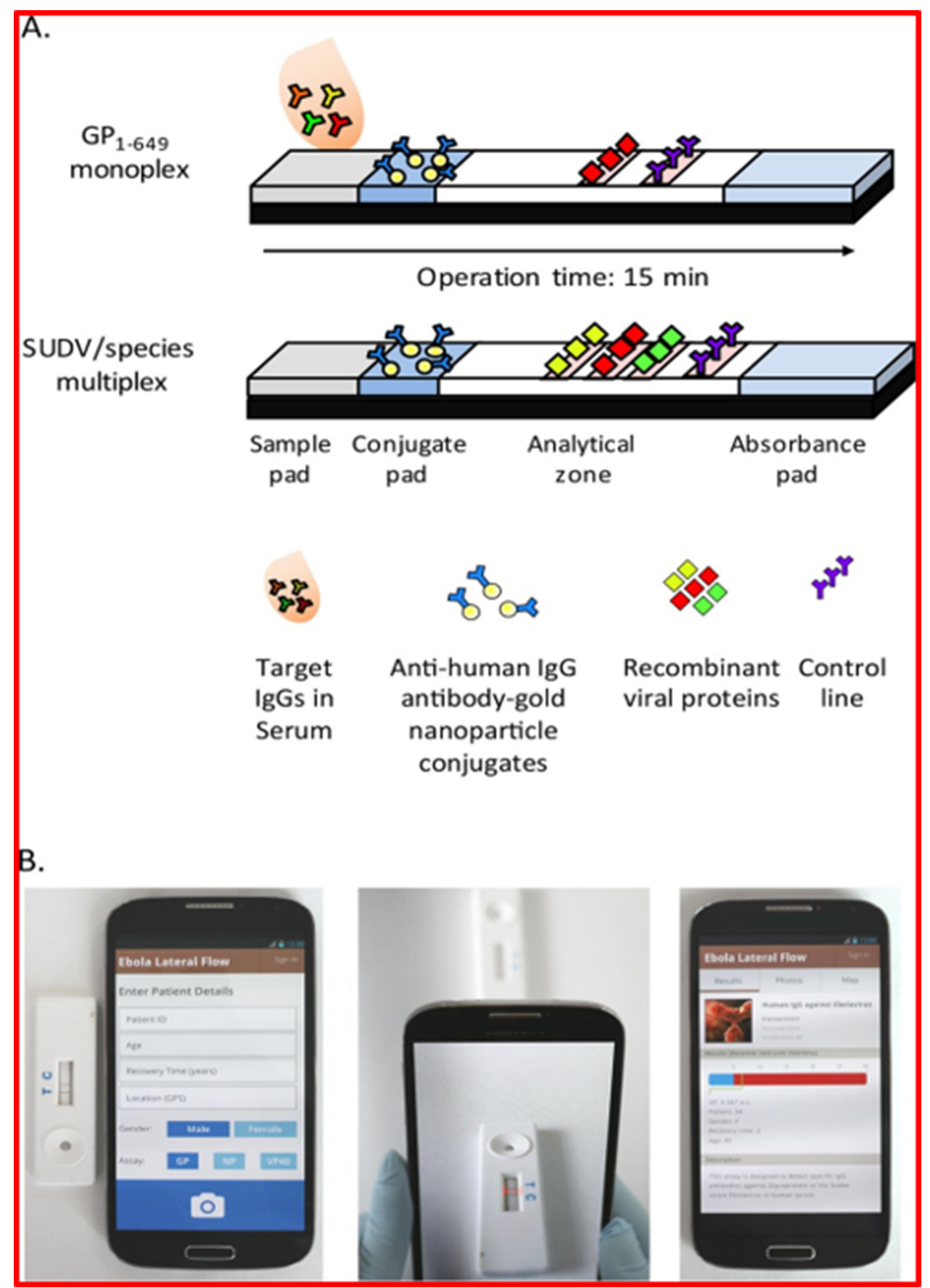

Figure 6 Overview of smartphone-based lateral flow POC test for detection of Ebola-specific antibodies illustrating (A) lateral flow strips and (B) smartphone applicationinterface login window for providing a description of the test and further recording of patient details.

Note: Reproduced with the permission from Brangel P, Sobarzo A, Parolo C, Miller BS, Howes PD, Gelkop S, Lutwama J], Dye JM, McKendry RA, Lobel L, Stevens MM. A serological point-of-care test for the detection of IgG antibodies against Ebola virus in human survivors. ACS nano. 20I8 I2(I):63-73. Copyright (2018) American Chemical Society. ${ }^{152}$

immunochromatographic strip has been reported by Brangel et al $^{152}$ for detection of Ebola-specific antibodies in human survivors. After analyzing 121 serum samples (of which 90 samples from Sudan virus human survivors and 31 from non-infected controls), this POC test kit offered an excellent sensitivity of $100 \%$ along with $98 \%$ specificity, compared with standard whole antigen ELISA (Figure 6).

\section{Towards Point-of-Care Diagnostics of COVID-19}

Further, the recent outbreak of corona virus (COVID-19) paved the way for advances in rapid and POC diagnostics that might help restrain it. ${ }^{153}$ The COVID-19 tests can be grouped as antigen, serological, ancillary, and nucleic acid tests (NAT). Among these, NAT is most widely used for 


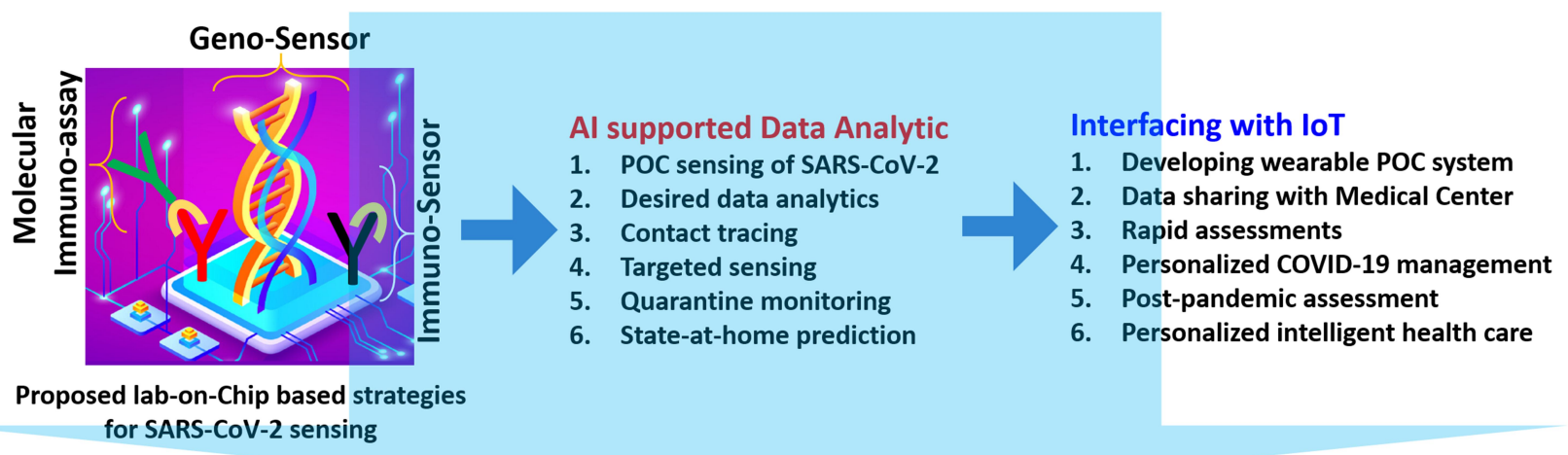

\section{Towards intelligent diagnostics for personalized COVID-19 management}

Figure 7 Strategic illustration of developing a miniaturized COVID-19 diagnostics tool for POC application.

Note: Reproduced with the permission from Mujawar MA, Gohel H, Bhardwaj SK, Srinivasan S, Hickman N, Kaushik A. Aspects of nano-enabling biosensing systems for intelligent healthcare; towards COVID-19 management. Materials Today Chemistry. 2020 5:100306. Copyright (2020) Elsevier. ${ }^{154}$

COVID-19 diagnosis in which viral RNA is reverse transcribed into DNA, followed by amplification through PCR. The present situation highly demands POC strategies to stop the outbreaks of these highly infectious diseases, as illustrated in Figure $7{ }^{154}$ In order to manage the COVID-19 pandemic, the nano-enabled biosensors in combination with artificial intelligence (AI) and internet of things (IoT) can be used in combination for development of smart sensing systems. ${ }^{155}$ Such smart systems can help in real-time detection of COVID-19 and tracing of the infected population. Right now, POC test kits for diagnosis of COVID-19 are in the developmental phase and some of these have already been introduced in the market to manage its outbreak, eg, Acro Biotech COVID-19 15-minute RAPID POC test (based on lateral flow immunoassay), ${ }^{156}$ and $\mathrm{Xpert}^{\circledR}$ Xpress SARS-CoV-2 (nucleic acid-based), ${ }^{158}$ and iAMP COVID-19 Detection Kit (nucleic acid-based). ${ }^{156-160}$ No doubt, these NAT-based tests take less than 1 hour for detection of COVID-19, their use is limited to laboratories only due to their bulky size and complex procedure.

\section{Challenges, Prospects, and Viewpoint}

The POC testing is very effective in controlling the increased prevalence of infectious/chronic diseases. Although POC techniques provide robust and rapid detection methods, various challenges must be met to continue their development. The major concern for POC testing is to achieve the improvement in accuracy and precision of diagnosis (either pre-analytical or analytical diagnosis) at various stages. Particularly in cases of pre-analytical diagnostics, appropriate sample handling approaches are required to reduce errors during sampling and measurement. Sample pre-processing is also another important factor to be considered, especially in quantitative analysis of target analyte from complex sample matrices. Particularly for infectious disease diagnosis, the sample could take different forms, such as urine, serum, blood, plasma, stool, or saliva. The different physical properties and chemical compositions of these samples demands proper and appropriate approaches that can accommodate the target analyte in an acceptable form. The POC testing platforms must possess the integration of separation devices and approaches for detection of target analyte in complex biofluid samples without interfering with other species present in the sample. Integration of biological samples should be performed appropriately to ensure the proper reaction in the assay. Moreover, suitable enrichment techniques can be used in POC testing for detection of analyte, even at very low concentrations. This will ultimately help in the early detection of pathogenic targets like bacteria or tumor cells, which remain present in very small numbers in early stages of diseases. From the view point of analytical diagnostics, further developments are required to improve the specificity and sensitivity of diagnostics to reduce false positive and false negative results, respectively. The results of POC devices should be comparable to laboratory-based assays. Moreover, POC guidelines also demand high levels of stability and reproducibility before commercialization. Besides LFA, the microfluidic devices can offer significant benefits including requirement of small sample volumes, possibilities of high throughput screening of biological species, and precise control 
of multiple samples. Over the past decade, the scientific achievements in microfluidics should be parlayed into practical implementation of POC diagnostics, eg, i) simplified microchannels and their integration with other components and ii) development of low cost and high throughput manufacturing processes for microfluidic cassettes.

The successful developments in POC testing are continued to speed the diagnosis of many critical diseases. The nanosized POC devices are an attractive field of research due to their immense potential in biomedical applications. The development of POC devices is still in its infancy and requires significant progress to ensure the high selectivity and sensitivity of the final products with reduced medical costs.

\section{Acknowledgments}

Sandeep Kumar thanks DBT, Govt. of India, for a research grant vide letter, No. BT/PR18868/BCE/8/1370/2016 dated 31-01-2018 and DST-PURSE sanctioned to GJUS\&T, Hisar under the PURSE program No. SR/PURSE Phase 2/ $40(\mathrm{G})$. KHK acknowledges support from grants from the National Research Foundation of Korea (NRF) funded by the Ministry of Science, ICT, \& Future Planning (No. 2016R1E1A1A01940995).

\section{Author Contributions}

All authors made a significant contribution to the work reported, whether that is in the conception, study design, execution, acquisition of data, analysis and interpretation, or in all these areas; took part in drafting, revising, or critically reviewing the article; gave final approval of the version to be published; have agreed on the journal to which the article has been submitted; and agree to be accountable for all aspects of the work.

\section{Disclosure}

The authors report no conflicts of interest for this work.

\section{References}

1. Granger D, Leo Y, Lee L, Theel E. Serodiagnosis of dengue virus infection using commercially available antibody and NS1 antigen ELISAs. Diagn Microbiol Infect Dis. 2017;88:120. doi:10.1016/j. diagmicrobio.2017.03.015

2. Tan Q, Hildon ZJ-L, Singh S, et al. Comparing patient and healthcare worker experiences during a dengue outbreak in Singapore: understanding the patient journey and the introduction of a point-of-care test (POCT) toward better care delivery. BMC Infect. Dis. 2017;17:503. doi:10.1186/s12879-017-2580-9

3. Desai AN, Kraemer MUG, Bhatia S, et al. Real-time epidemic forecasting: challenges and opportunities. Health Security. 2019;17:268. doi:10.1089/hs.2019.0022
4. Hansen GT. Point-of-care testing in microbiology: a mechanism for improving patient outcomes. Clin Chem. 2020;66:124. doi:10.1373/clinchem.2019.304782

5. Udugama B, Kadhiresan P, Kozlowski HN, et al. Diagnosing COVID-19: the disease and tools for detection. ACS Nano. 2020;14:3822. doi:10.1021/acsnano.0c02624

6. Malekjahani A, Sindhwani S, Syed AM, Chan WCW. Engineering steps for mobile point-of-care diagnostic devices. Acc Chem Res. 2019;52:2406. doi:10.1021/acs.accounts.9b00200

7. Li F, You M, Li S, et al. Paper-based point-of-care immunoassays: recent advances and emerging trends. Biotechnol Adv. 2020;39:107442. doi:10.1016/j.biotechadv.2019.107442

8. Ong DSY, Poljak M. Smartphones as mobile microbiological laboratories. Clin Microbiol Infect. 2020;26:421. doi:10.1016/j. cmi.2019.09.026

9. Soh JH, Chan HM, Ying JY. Strategies for developing sensitive and specific nanoparticle-based lateral flow assays as point-ofcare diagnostic device. Nano Today. 2020;30:100831. doi:10.1016/j.nantod.2019.100831

10. Nasseri B, Soleimani N, Rabiee N, Kalbasi A, Karimi M, Hamblin MR. Point-of-care microfluidic devices for pathogen detection. Biosens Bioelectron. 2018;117:112. doi:10.1016/j. bios.2018.05.050

11. Kumar S, Nehra M, Mehta J, Dilbaghi N, Marrazza G, Kaushik A. Point-of-care strategies for detection of waterborne pathogens. Sensors. 2019;19:4476. doi:10.3390/ s19204476

12. Point of Care Diagnostics Market to Reach USD 28,379.6 Million by 2026; Developing Healthcare facilities in India will Foster Growth, states Fortune Business Insights ${ }^{\mathrm{TM}}$; n.d. Available from: https://www.globenewswire.com/news-release/2020/05/20/ 2036182/0/en/Point-of-Care-Diagnostics-Market-to-Reach-USD -28-379-6-Million-by-2026-Developing-Healthcare-facilities-inIndia-will-Foster-Growth-states-Fortune-Business-Insights.html. Accessed September 09, 2020.

13. Nayak S, Guo T, Lopez-Rios J, et al. Integrating user behavior with engineering design of point-of-care diagnostic devices: theoretical framework and empirical findings. Lab Chip. 2019;19:2241. doi:10.1039/C9LC00188C

14. Shandilya R, Bhargava A, Bunkar N, Tiwari R, Goryacheva IY, Mishra PK. Nanobiosensors: point-of-care approaches for cancer diagnostics. Biosens Bioelectron. 2019;130:147. doi:10.1016/j. bios.2019.01.034

15. Garattini C, Raffle J, Aisyah DN, Sartain F, Kozlakidis Z. Big data analytics, infectious diseases and associated ethical impacts. Philos Technol. 2019;32:69. doi:10.1007/s13347-0170278-y

16. Song Y, Gyarmati P. Rapid DNA detection using filter paper. N Biotechnol. 2020;55:77. doi:10.1016/j.nbt.2019.10.005

17. Zhang YJ, Chen S, Yu YL, Wang JH. A miniaturized photoacoustic device with laptop readout for point-of-care testing of blood glucose. Talanta. 2020;209:120527. doi:10.1016/j. talanta.2019.120527

18. Free AH, Adams EC, Kercher ML, Free HM, Cook MH. Simple specific test for urine glucose. Clin Chem. 1957;3:163. doi:10.1093/clinchem/3.3.163

19. Yetisen AK, Akram MS, Lowe CR. Paper-based microfluidic point-of-care diagnostic devices. Lab Chip. 2013;13:2210. doi:10.1039/c3lc50169h

20. Banerjee R, Jaiswal A. Recent advances in nanoparticle-based lateral flow immunoassay as a point-of-care diagnostic tool for infectious agents and diseases. Analyst. 2018;143:1970. doi:10.1039/C8AN00307F

21. Pandey CM, Augustine S, Kumar S, et al. Microfluidics based point-of-care diagnostics. Biotechnol J. 2018;13:1700047. doi:10.1002/biot.201700047 
22. Kumar S, Nehra M, Dilbaghi N, Marrazza G, Hassan AA, Kim KH. Nano-based smart pesticide formulations: emerging opportunities for agriculture. J Control Release. 2019;294:131. doi:10.1016/j.jconrel.2018.12.012

23. Luo Z, Lv T, Zhu K, et al. Paper-based ratiometric fluorescence analytical devices towards point-of-care testing of human serum albumin. Angew Chem. 2020;132:3155. doi:10.1002/ange.201915046

24. Xu W, Wang D, Li D, Liu CC. Recent developments of electrochemical and optical biosensors for antibody detection. Int $\mathrm{J} \mathrm{Mol}$ Sci. 2019;21:134. doi:10.3390/ijms21010134

25. Fabri-Faja N, Calvo-Lozano O, Dey P, et al. Early sepsis diagnosis via protein and miRNA biomarkers using a novel point-ofcare photonic biosensor. Anal Chim Acta. 2019;1077:232. doi:10.1016/j.aca.2019.05.038

26. Nie R, Huang J, Xu X, Yang L. A portable pencil-like immunosensor for point-of-care testing of inflammatory biomarkers. Anal Bioanal Chem. 2020;412:3231. doi:10.1007/s00216-020-02582-z

27. Drain PK, Dorward J, Bender A, et al. Point-of-care HIV viral load testing: an essential tool for a sustainable global HIV/AIDS response. Clin Microbiol Rev. 2019;32:e0097. doi:10.1128/CMR.00097-18

28. Urusov AE, Zherdev AV, Dzantiev BB. Towards lateral flow quantitative assays: detection approaches. Biosensors. 2019;9:89. doi:10.3390/bios9030089

29. Chen A, Yang S. Replacing antibodies with aptamers in lateral flow immunoassay. Biosens Bioelectron. 2015;71:230. doi:10.1016/j.bios.2015.04.041

30. Mak WC, Beni V, Turner APF. Lateral-flow technology: from visual to instrumental. Trends Anal Chem. 2016;79:297. doi:10.1016/j.trac.2015.10.017

31. Sajid M, Kawde A, Daud M. Designs, formats and applications of lateral flow assay: a literature review. J. Saudi Chem. Soc. 2015;19 (6):689.

32. Mejía-Salazar JR, Cruz KR, Vásques EMM, de Oliveira ON. Microfluidic point-of-care devices: new trends and future prospects for eHealth diagnostics. Sensors (Switzerland). 2020;20:1951. doi:10.3390/s20071951

33. Walsh DI, Kong DS, Murthy SK, Carr PA. Enabling microfluidics: from clean rooms to makerspaces. Trends Biotechnol. 2017;35(383):383-392. doi:10.1016/j.tibtech.2017.01.001

34. Shaw JLV. Practical challenges related to point of care testing. Pract Lab Med. 2016;4:22. doi:10.1016/j.plabm.2015.12.002

35. de Haan K, Ceylan Koydemir H, Rivenson Y, et al. Automated screening of sickle cells using a smartphone-based microscope and deep learning. Npj Digit Med. 2020;3:76. doi:10.1038/ s41746-020-0282-y

36. Mettakoonpitak J, Boehle K, Nantaphol S, et al. Electrochemistry on paper-based analytical devices: a review. Electroanalysis. 2016;28:1420. doi:10.1002/elan.201501143

37. Adekanmbi EO, Srivastava SK. Dielectrophoretic applications for disease diagnostics using lab-on-a-chip platforms. Lab Chip. 2016;16:2148. doi:10.1039/C6LC00355A

38. Zhu Y, Meng X, Chen Y, et al. Self-served and fully automated biochemical detection of finger-prick blood at home using a portable microfluidic analyzer. Sens Actuators B Chem. 2020;303:127235. doi:10.1016/j.snb.2019.127235

39. Dincer C, Bruch R, Kling A, Dittrich PS, Urban GA. Multiplexed Point-of-care testing - xPOCT. Trends Biotechnol. 2017;35 (8):728-742. doi:10.1016/j.tibtech.2017.03.013

40. Dao Dong H, Hong Huang L, yang Liu D, et al. Robust and multiplexed colorimetric immunoassay for cardiovascular disease biomarkers detection in serum with high specificity. Microchem J. 2020;152:104334. doi:10.1016/j.microc.2019.104334

41. Du J, Wu S, Niu L, Li J, Zhao D, Bai Y. A gold nanoparticles-assisted multiplex PCR assay for simultaneous detection of Salmonella typhimurium, Listeria monocytogenes and Escherichia coli O157: H7. Anal Methods. 2020;12:212. doi:10.1039/C9AY02282A
42. Laksanasopin T, Guo TW, Nayak S, et al. A smartphone dongle for diagnosis of infectious diseases at the point of care. Sci Transl Med. 2015;7:273re1. doi:10.1126/scitranslmed.aaa0056

43. iHealth official site for smart blood pressure monitor, glucose meter, scale \& more; n.d. Available from: https://ihealthlabs. com/. Accessed September 26, 2020.

44. Shen L, Hagen JA, Papautsky I. Point-of-care colorimetric detection with a smartphone. Lab Chip. 2012;12(21):4240. doi:10.1039/c2lc40741h

45. Zhu H, Mavandadi S, Coskun AF, Yaglidere O, Ozcan A. Optofluidic fluorescent imaging cytometry on a cell phone. Anal Chem. 2011;83:6641. doi:10.1021/ac201587a

46. Linder E, Grote A, Varjo S, et al. On-chip imaging of Schistosoma haematobium eggs in urine for diagnosis by computer vision. PLoS Negl Trop Dis. 2013;7:e2547. doi:10.1371/journal.pntd.0002547

47. Hu J, Wang S, Wang L, et al. Advances in paper-based point-ofcare diagnostics. Biosens Bioelectron. 2014;54:585. doi:10.1016/ j.bios.2013.10.075

48. Du Y, Pothukuchy A, Gollihar JD, Nourani A, Li B, Ellington AD. Coupling sensitive nucleic acid amplification with commercial pregnancy test strips. Angew Chemie Int Ed. 2017;56:992. doi:10.1002/anie.201609108

49. van den Berk GEL, Frissen PHJ, Regez RM, Rietra PJGM. Evaluation of the rapid immunoassay determine HIV $1 / 2$ for detection of antibodies to human immunodeficiency virus types 1 and 2. J Clin Microbiol. 2003;41:3868. doi:10.1128/ JCM.41.8.3868-3869.2003

50. Yang Q, Gong X, Song T, et al. Quantum dot-based immunochromatography test strip for rapid, quantitative and sensitive detection of alpha fetoprotein. Biosens Bioelectron. 2011;30:145. doi:10.1016/j.bios.2011.09.002

51. Malhotra K, Noor MO, Krull UJ. Detection of cystic fibrosis transmembrane conductance regulator $\Delta \mathrm{F} 508$ gene mutation using a paper-based nucleic acid hybridization assay and a smartphone camera. Analyst. 2018;143:3049. doi:10.1039/C8AN00509E

52. Dos Santos GP, Corrêa CC, Kubota LT. A simple, sensitive and reduced cost paper-based device with low quantity of chemicals for the early diagnosis of Plasmodium falciparum malaria using an enzyme-based colorimetric assay. Sens Actuators B Chem. 2018;255:2113. doi:10.1016/j.snb.2017.09.005

53. Tian R, Li Y, Bai J. Hierarchical assembled nanomaterial paper based analytical devices for simultaneously electrochemical detection of microRNAs. Anal Chim Acta. 2019;1058:89. doi:10.1016/j.aca.2019.01.036

54. Gong MM, Sinton D. Turning the page: advancing paper-based microfluidics for broad diagnostic application. Chem Rev. 2017;117:8447. doi:10.1021/acs.chemrev.7b00024

55. Abaxis | better at Point of Care; n.d. Available from: https://www. abaxis.com/medical. Accessed September 26, 2020.

56. Liu Q, Zhang X, Chen L, et al. A sample-to-answer labdisc platform integrated novel membrane-resistance valves for detection of highly pathogenic avian influenza viruses. Sens Actuators $B$ Chem. 2018;270:371. doi:10.1016/j.snb.2018.05.044

57. Siloam Biosciences - TROVA ${ }^{\mathrm{TM}}$ Point of Care Testing (POCT) system; n.d. Available from: http://siloambio.com/lifescienceproducts/ point of care test poct platform/. Accessed September 26, 2020.

58. AlphaLISA Immunoassay Kits; n.d. Available from: https://www. perkinelmer.com/lab-products-and-services/application-supportknowledgebase/alphalisa-alphascreen-no-wash-assays/immunoas say-kits.html. Accessed September 26, 2020.

59. SD BIOLINE Dengue Duo (Dengue NS1 Ag + IgG/IgM) | rapid point of care diagnostics - abbott; n.d. Available from: https:// www.globalpointofcare.abbott/en/product-details/sd-bioline-den gue-duo-ns1-ag_ab-combo.html. 
60. Panbio Dengue Early Rapid | rapid point of care diagnostics abbott; n.d. Available from: https://www.globalpointofcare.abbott/ en/product-details/panbio-dengue-early-rapid-au.html. Accessed September 26, 2020.

61. Dengue NS1 Rapid test (Strip) (DTS349) - Creative Diagnostics; n.d. Available from: https:/www.creative-diagnostics.com/ Dengue-NS1-Rapid-test-106576-167.htm. Accessed September 26, 2020.

62. ACCESSBIO; n.d. Available from: http://www.accessbio.net/eng/ products/products01_03.asp. Accessed September 26, 2020.

63. bhatbiotech.com; n.d. Available from: http://bhatbiotech.com/den gue-range.php. Accessed September 26, 2020.

64. Products - STANDARD Q Dengue Duo; n.d. Available from: http://sdbiosensor.com/xe/product/2546? category=2306. Accessed September 26, 2020.

65. Alere Determine TB LAM Ag | rapid point of care diagnostics - abbott; n.d. Available from: https://www.globalpointofcare.abbott/en/productdetails/determine-tb-lam.html. Accessed September 26, 2020.

66. Deng S, Sun Y, Xia H, et al. Accuracy of commercial molecular diagnostics for the detection of pulmonary tuberculosis in China: a systematic review. Sci Rep. 2019;9:4553. doi:10.1038/s41598-01941074-8

67. Ustar Biotechnologies; n.d. Available from: http://www.bioustar.com/ en/newsdetail.aspx?NewsId=181\&cateid=194. Accessed September 26, 2020 .

68. Tuberculosis IgM/IgG Rapid Test (DTS514) - Creative Diagnostics; n.d. Available from: https://www.creativediagnostics.com/TB-IgM-IgG-Rapid-Test-110826-453.htm. Accessed September 26, 2020.

69. HBsAg Rapid Test (strip) - CTK Biotech; n.d. Available from: https:// ctkbiotech.com/product/hbsag-rapid-test-strip/. Accessed September $26,2020$.

70. Alere Determine HBsAg | rapid point of care diagnostics - abbott; n.d. Available from: https://www.globalpointofcare.abbott/en/pro duct-details/determine-hbsag.html. Accessed September 26, 2020.

71. Lee M-K, Kweon OJ, Lim YK, Kim H-R, Kim T-H. P0804 Performance evaluation of the EuDx-HE (A,B,C) kit for pointof-care testing of hepatitis $\mathrm{A}, \mathrm{B}$, and $\mathrm{C}$ viruses in patients with viral hepatitis. 29th ECCMID, Congr. ESCMID, Amsterdam, Netherlands; 2019.

72. SD BIOLINE HBsAg | rapid point of care diagnostics - abbott; $n$. d. Available from: https://www.globalpointofcare.abbott/en/pro duct-details/sd-bioline-hbsag.html. Accessed September 26, 2020.

73. Alere Determine HIV-1/2 | rapid point of care diagnostics abbott; n.d. Available from: https://www.globalpointofcare. abbott/en/product-details/determine-hiv-1-2.html. Accessed September 26, 2020.

74. Chembio | DPP ${ }^{\circledR}$ HIV $1 / 2$ Assay; n.d. Available from: http://chem bio.com/dpp-hiv-12-assayintl/. Accessed September 26, 2020.

75. OraSure Technologies - OraQuick ADVANCE ${ }^{\circledR}$ Rapid HIV-1/ 2 Antibody Test; n.d. Available from: https://www.orasure.com/ products-infectious/products-infectious-oraquick.asp. Accessed September 26, 2020.

76. BTNX | products; n.d. Available from: https://www.btnx.com/ Product?id=1656. Accessed September 26, 2020.

77. INSTI HIV-1/HIV-2 Antibody Test | INSTI; n.d. Available from: https://insti.com/hiv-test/. Accessed September 26, 2020.

78. Zika virus test kit - QuickProfile ${ }^{\mathrm{TM}}$ - LumiQuick Diagnostics $\mathrm{IgG/IgM/serum;} \mathrm{n.d.} \mathrm{Available} \mathrm{from:} \mathrm{https://www.medicalexpo.}$ com/prod/lumiquick-diagnostics/product-69152-826696.html. Accessed September 26, 2020.

79. Brady OJ, Gething PW, Bhatt S, et al. Refining the global spatial limits of dengue virus transmission by evidence-based consensus. PLoS Negl Trop Dis. 2012;6:e1760. doi:10.1371/journal. pntd.0001760
80. Andries A-C, Duong V, Ong S, et al. Evaluation of the performances of six commercial kits designed for dengue NS1 and anti-dengue IgM, IgG and IgA detection in urine and saliva clinical specimens. BMC Infect Dis. 2016;16:201. doi:10.1186/s12879-016-1551-x

81. Velay A, Solis M, Barth H, et al. Comparison of six commercial tick-borne encephalitis IgM and IgG ELISA kits and the molecular characterization of their antigenic design. Diagn Microbiol Infect Dis. 2018;90:286. doi:10.1016/j.diagmicrobio.2017.12.012

82. Wang R, Ongagna-Yhombi SY, Lu Z, et al. Rapid diagnostic platform for colorimetric differential detection of dengue and Chikungunya viral infections. Anal Chem. 2019;91:5415. doi:10.1021/acs.analchem.9b00704

83. Choi JR, Yong KW, Tang R, et al. Lateral flow assay based on paper-hydrogel hybrid material for sensitive point-of-care detection of dengue virus. Adv Healthc Mater. 2017;6:1600920. doi:10.1002/adhm.201600920

84. Minero GAS, Nogueira C, Rizzi G, et al. Sequence-specific validation of LAMP amplicons in real-time optomagnetic detection of Dengue serotype 2 synthetic DNA. Analyst. 2017;142:3441. doi:10.1039/C7AN01023K

85. Park BH, Oh SJ, Jung JH, et al. An integrated rotary microfluidic system with DNA extraction, loop-mediated isothermal amplification, and lateral flow strip based detection for point-of-care pathogen diagnostics. Biosens Bioelectron. 2017;91:334. doi:10.1016/j.bios.2016.11.063

86. Data \& Statistics | TB | CDC; n.d. Available from: https://www. cdc.gov/tb/statistics/default.htm. Accessed September 26, 2020.

87. WHO; 2019. Available from: https://www.who.int/tb/publica tions/global_report/en/. Accessed September 26, 2020 ..

88. Izudi J, Tamwesigire IK, Bajunirwe F. Treatment supporters and level of health facility influence completion of sputum smear monitoring among tuberculosis patients in rural Uganda: a mixed-methods study. Int J Infect Dis. 2020;91:149. doi:10.1016/j.ijid.2019.12.003

89. Walzl G, McNerney R, Du Plessis N, et al. Tuberculosis: advances and challenges in development of new diagnostics and biomarkers. Lancet Infect Dis. 2018;18:e199. doi:10.1016/S14733099(18)30111-7

90. Dorman SE, Schumacher SG, Alland D, et al. Xpert MTB/RIF Ultra for detection of Mycobacterium tuberculosis and rifampicin resistance: a prospective multicentre diagnostic accuracy study. Lancet Infect Dis. 2018;18:76. doi:10.1016/S1473-3099(17)30691-6

91. Sánchez C, Santos JP, Lozano J. Use of electronic noses for diagnosis of digestive and respiratory diseases through the breath. Biosensors. 2019;9:35. doi:10.3390/bios9010035

92. García-Basteiro AL, DiNardo A, Saavedra B, et al. Point of care diagnostics for tuberculosis. Rev Port Pneumol. 2018;24:73. doi:10.1016/j.rppnen.2017.12.002

93. Cheng Y, Xie H, Sule P, et al. Fluorogenic Probes with Substitutions at the 2 and 7 Positions of Cephalosporin are Highly BlaC-Specific for Rapid Mycobacterium tuberculosis Detection. Angew Chemie Int Ed. 2014;53:9360. doi:10.1002/anie.201405243

94. Amin AG, De P, Spencer JS, et al. Detection of lipoarabinomannan in urine and serum of HIV-positive and HIV-negative TB suspects using an improved capture-enzyme linked immuno absorbent assay and gas chromatography/mass spectrometry. Tuberculosis. 2018;111:178. doi:10.1016/j.tube.2018.06.004

95. Broger T, Sossen B, Du Toit E, et al. Novel lipoarabinomannan point-of-care tuberculosis test for people with HIV: a diagnostic accuracy study. Lancet Infect Dis. 2019;19:852. doi:10.1016/ S1473-3099(19)30001-5

96. Li L, Liu Z, Zhang H, Yue W, Li C-W, Yi C. A point-of-need enzyme linked aptamer assay for Mycobacterium tuberculosis detection using a smartphone. Sens Actuators B Chem. 2018;254 (337). doi:10.1016/j.snb.2017.07.074 
97. Liong M, Hoang AN, Chung J, et al. Magnetic barcode assay for genetic detection of pathogens. Nat Commun. 2013;4:1752. doi: $10.1038 /$ ncomms 2745

98. Barroso TG, Martins RC, Fernandes E, Cardoso S, Rivas J, Freitas PP. Detection of BCG bacteria using a magnetoresistive biosensor: A step towards a fully electronic platform for tuberculosis point-of-care detection. Biosens Bioelectron. 2018;100:259. doi:10.1016/j. bios.2017.09.004

99. Chen Y, Guo S, Zhao M, et al. Amperometric DNA biosensor for Mycobacterium tuberculosis detection using flower-like carbon nanotubes-polyaniline nanohybrid and enzyme-assisted signal amplification strategy. Biosens Bioelectron. 2018;119:215. doi:10.1016/j. bios.2018.08.023

100. World Hepatitis Day 2019; n.d. Available from: https:/www.who.int/ campaigns/world-hepatitis-day/2019. Accessed September 26, 2020.

101. Andersson MI, Rajbhandari R, Kew MC, et al. Mother-to-child transmission of hepatitis B virus in sub-Saharan Africa: time to act. Lancet Glob Health. 2015;3:e358. doi:10.1016/S2214-109X(15)00056-X

102. Zhang X, Zhu X, Ji Y, et al. Increased risk of hepatitis B virus infection amongst individuals with diabetes mellitus. Biosci Rep. 2019;39:BSR20181715. doi:10.1042/BSR20181715

103. Duchesne L, Lacombe K. Innovative technologies for point-ofcare testing of viral hepatitis in low-resource and decentralized settings. J Viral Hepat. 2018;25:108. doi:10.1111/jvh.12827

104. Complete list of donor screening assays for infectious agents and HIV diagnostic assays | FDA; n.d. Available from: https://www.fda.gov/vac cines-blood-biologics/complete-list-donor-screening-assays-infectiousagents-and-hiv-diagnostic-assays. Accessed September 26, 2020.

105. Shimakawa Y, Ndow G, Njie R, et al. Hepatitis B core-related antigen: an alternative to hepatitis B virus DNA to assess treatment eligibility in Africa. Clin Infect Dis. 2019;70:1442. doi:10.1093/cid/ciz412

106. Tsaloglou M-N, Nemiroski A, Camci-Unal G, et al. Handheld isothermal amplification and electrochemical detection of DNA in resource-limited settings. Anal Biochem. 2018;543:116. doi:10.1016/j.ab.2017.11.025

107. Srisomwat C, Teengam $P$, Chuaypen N, Tangkijvanich $P$, Vilaivan T, Chailapakul O. Pop-up paper electrochemical device for label-free hepatitis B virus DNA detection. Sens Actuators B Chem. 2020;316(128077). doi:10.1016/j.snb.2020.128077

108. Barbosa JR, Cortes VF, Portilho MM, et al. Performance of point of care assays for hepatitis $\mathrm{B}$ and $\mathrm{C}$ viruses in chronic kidney disease patients. J Clin Pathol. 2018;71:879. doi:10.1136/jclinpath-2018-205024

109. Coffin CS, Zhou K, Terrault NA. New and old biomarkers for diagnosis and management of chronic hepatitis $\mathrm{B}$ virus infection Gastroenterology. 2019;156:355. doi:10.1053/j.gastro.2018.11.037

110. Qiu X, Song L, Yang S, et al. A fast and low-cost genotyping method for hepatitis B virus based on pattern recognition in pointof-care settings. Sci Rep. 2016;6:28274. doi:10.1038/srep28274

111. VIKIA ${ }^{\circledR} \mathrm{HBs}$ Ag | bioMérieux India; n.d. Available from: https:// www.biomerieuxindia.in/product/vikiar-hbs-ag. Accessed September 26, 2020.

112. Lumiquick Diagnostics, Inc - diagnostics products, medical devices; n.d. Available from: https://umiquick.co/. Accessed September 26, 2020.

113. Alere Determine HBsAg - Alere is now Abbott; n.d. Available from: https://www.alere.com/en/home/product-details/determinehbsag.html. Accessed September 26, 2020.

114. Kweon OJ, Lim YK, Kim HR, Kim T, Lee M. Analytical performance of newly developed rapid point-of-care test for the simultaneous detection of hepatitis $\mathrm{A}, \mathrm{B}$, and $\mathrm{C}$ viruses in serum samples. J Med Virol. 2019;91:1056. doi:10.1002/jmv.25405

115. Parry JV, Easterbrook P, Sands AR. One or two serological assay testing strategy for diagnosis of HBV and HCV infection? The use of predictive modelling. BMC Infect Dis. 2017;17:705. doi:10.1186/ s12879-017-2774-1
116. Peeling RW, Boeras DI, Marinucci F, Easterbrook P. The future of viral hepatitis testing: innovations in testing technologies and approaches. BMC Infect Dis. 2017;17:699. doi:10.1186/s12879017-2775-0

117. Viall AH, McCray E, Mermin J, Wortley P. Current and (potential) future effects of the affordable care act on HIV prevention. Curr HIV/AIDS Rep. 2016;13:95. doi:10.1007/s11904-016-0306-z

118. Allem J-P, Leas EC, Caputi TL, et al. The Charlie Sheen effect on rapid in-home human immunodeficiency virus test sales. Prev Sci. 2017;18:541. doi:10.1007/s11121-017-0792-2

119. Gearhart TL, Montelaro RC, Schurdak ME, et al. Selection of a potential diagnostic biomarker for HIV infection from a random library of non-biological synthetic peptoid oligomers. J Immunol Methods. 2016;435:85. doi:10.1016/j.jim.2016.05.001

120. Byrnes SA, Weigl BH. Selecting analytical biomarkers for diagnostic applications: a first principles approach. Expert Rev Mol Diagn. 2018;18:19. doi:10.1080/14737159.2018.1412258

121. Galli RA, Green KF, La Marca A, et al. Evaluation of the accuracy and ease of use of a rapid HIV-1 Antibody Test performed by untrained operators at the point of care. J Clin Virol. 2013;58:e65. doi:10.1016/j.jcv.2013.08.024

122. Kaushik A, Jayant RD, Nair M. Advancements in nano-enabled therapeutics for neuroHIV management. Int $J$ Nanomedicine. 2016;11:4317. doi:10.2147/IJN.S109943

123. Technau K-G, Kuhn L, Coovadia A, Murnane PM, Sherman G. Xpert HIV-1 point-of-care test for neonatal diagnosis of HIV in the birth testing programme of a maternity hospital: a field evaluation study. Lancet HIV. 2017;4:e442. doi:10.1016/S2352-3018 (17)30097-8

124. Gueudin M, Baron A, Alessandri-Gradt E, et al. Performance evaluation of the new HIV-1 quantification assay, Xpert HIV-1 viral load, on a wide panel of HIV-1 variants. J Acquir Immune Defic Syndr. 2016;72:521. doi:10.1097/QAI.0000000000001003

125. Nair SV, Kim HC, Fortunko J, et al. Aptima HIV-1 Quant Dx-a fully automated assay for both diagnosis and quantification of HIV-1. J Clin Virol. 2016;77:46. doi:10.1016/j.jcv.2016.02.002

126. Mor O, Gozlan Y, Wax M, et al. Evaluation of the RealTime HIV1, Xpert HIV-1, and Aptima HIV-1 Quant Dx Assays in comparison to the NucliSens EasyQ HIV-1 v2.0 Assay for quantification of HIV-1 viral load. J Clin Microbiol. 2015;53:3458. doi:10.1128/ JCM.01806-15

127. Adams S, Luo W, Wesolowski L, et al. Performance evaluation of the point-of-care INSTI TM HIV-1/2 antibody test in early and established HIV infections. J Clin Virol. 2017;91:90. doi:10.1016/j.jcv.2017.03.012

128. Nkenfou C, Kembou J, Temgoua E, et al. Evaluation of Oraquick ${ }^{\circledR}$ HIV-1/2 as oral rapid test. African $J$ Infect Dis. 2013;7:27. doi:10.4314/ajid.v7i2.2

129. Kaushik A, Madhavan NA, inventors. US9759709B1 - Devices and Methods to Monitor HIV-Infection in Presence of Substance of Abuse and/or Therapeutic Agent - Google Patents. 2017.

130. Kaushik A, Vabbina PK, Atluri V, et al. Electrochemical monitoring-on-chip (E-MoC) of HIV-infection in presence of cocaine and therapeutics. Biosens Bioelectron. 2016;86:426. doi:10.1016/j. bios.2016.06.086

131. Wabuyele MB, Vo-Dinh T. Detection of human immunodeficiency virus type 1 DNA sequence using plasmonics nanoprobes. Anal Chem. 2005;77:7810. doi:10.1021/ac0514671

132. Fu X, Cheng Z, Yu J, Choo P, Chen L, Choo J. A SERS-based lateral flow assay biosensor for highly sensitive detection of HIV1 DNA. Biosens Bioelectron. 2016;78:530. doi:10.1016/j. bios.2015.11.099

133. Citartan M, Tang TH. Recent developments of aptasensors expedient for point-of-care (POC) diagnostics. Talanta. 2019;199:556. doi:10.1016/j.talanta.2019.02.066 
134. Li Z, Leustean L, Inci F, Zheng M, Demirci U, Wang S. Plasmonic-based platforms for diagnosis of infectious diseases at the point-of-care. Biotechnol Adv. 2019;37:107440. doi:10.1016/j.biotechadv.2019.107440

135. Diao W, Tang M, Ding S, et al. Highly sensitive surface plasmon resonance biosensor for the detection of HIV-related DNA based on dynamic and structural DNA nanodevices Biosens Bioelectron. 2018;100:228. doi:10.1016/j.bios.2017.08.042

136. Damhorst GL, Watkins NN, Bashir R. Micro-and nanotechnology for HIV/AIDS diagnostics in resource-limited settings. IEEE Trans Biomed Eng. 2013;60:715. doi:10.1109/TBME.2013.2244894

137. Tokel O, Inci F, Demirci U. Advances in plasmonic technologies for point of care applications. Chem Rev. 2014;114:5728. doi: $10.1021 / \mathrm{cr} 4000623$

138. Shafiee H, Wang S, Inci F, et al. Emerging technologies for pointof-care management of HIV infection. Annu Rev Med. 2015;66:387. doi:10.1146/annurev-med-092112-143017

139. Chunduri LAA, Kurdekar A, Haleyurgirisetty MK, Bulagonda EP, Kamisetti V, Hewlett IK. Femtogram level sensitivity achieved by surface engineered silica nanoparticles in the early detection of HIV infection. Sci Rep. 2017;7:7149. doi:10.1038/s41598-017-07299-1

140. Waggoner JJ, Pinsky BA. Zika virus: diagnostics for an emerging pandemic threat. J Clin Microbiol. 2016;54:860. doi:10.1128/ JCM.00279-16

141. Kaushik A, Madhavan NA, inventors. US10012645B2 - Rapid Zika Virus Detection Using Nano-Enabled Electrochemical Sensing System - Google Patents. 2018.

142. Kaushik A, Tiwari S, Jayant RD, et al. Electrochemical biosensors for early stage Zika diagnostics Trends Biotechnol. 2017;35 (308). doi:10.1016/j.tibtech.2016.10.001

143. Kaushik A, Yndart A, Kumar S, et al. A sensitive electrochemical immunosensor for label-free detection of Zika-virus protein. Sci Rep. 2018;8:9700. doi:10.1038/s41598-018-28035-3

144. Pardee K, Green AA, Takahashi MK, et al. Rapid, low-cost detection of Zika virus using programmable biomolecular components. Cell. 2016;165:1255. doi:10.1016/j.cell.2016.04.059

145. Song J, Mauk MG, Hackett BA, Cherry S, Bau HH, Liu C. Instrumentfree point-of-care molecular detection of Zika virus. Anal Chem. 2016;88:7289. doi:10.1021/acs.analchem.6b01632

146. Rong Z, Wang Q, Sun N, et al. Smartphone-based fluorescent lateral flow immunoassay platform for highly sensitive point-ofcare detection of Zika virus nonstructural protein 1. Anal Chim Acta. 2019;1055:140. doi:10.1016/j.aca.2018.12.043

147. Kabir MA, Zilouchian H, Sher M, Asghar W. Development of a flow-free automated colorimetric detection assay integrated with smartphone for Zika NS1. Diagnostics. 2020;10:42. doi:10.3390/ diagnostics 10010042
148. Kaushik A, Tiwari S, Dev Jayant R, Marty A, Nair M. Towards detection and diagnosis of Ebola virus disease at point-of-care. Biosens Bioelectron. 2016;75:254. doi:10.1016/j.bios.2015.08. 040

149. Ciftci S, Neumann F, Abdurahman S, et al. Digital rolling circle amplification-based detection of ebola and other tropical viruses. J Mol Diagn. 2020;22:272. doi:10.1016/j.jmoldx.2019.10.014

150. Qin P, Park M, Alfson KJ, et al. Rapid and fully microfluidic Ebola virus detection with CRISPR-Cas13a. ACS Sens. 2019;4:1048. doi:10.1021/acssensors.9b00239

151. Makiala S, Mukadi D, De Weggheleire A, et al. Clinical evaluation of QuickNavi ${ }^{\mathrm{TM}}$-Ebola in the 2018 outbreak of Ebola virus disease in the Democratic Republic of the Congo. Viruses. 2019;11:589. doi:10.3390/v11070589

152. Brangel P, Sobarzo A, Parolo C, et al. A serological point-of-care test for the detection of $\operatorname{IgG}$ antibodies against Ebola virus in human survivors. ACS Nano. 2018;12:63. doi:10.1021/ acsnano.7b07021

153. Nguyen T, Bang DD, Wolff A. 2019 novel coronavirus disease (COVID-19): paving the road for rapid detection and point-ofcare diagnostics. Micromachines. 2020;11:306. doi:10.3390/ mi11030306

154. Mujawar MA, Gohel H, Bhardwaj SK, Srinivasan S, Hickman N, Kaushik A. Nano-enabled biosensing systems for intelligent healthcare: towards COVID-19 management. Mater Today Chem. 2020;100306. doi:10.1016/j.mtchem.2020.100306

155. Morales-Narváez E, Dincer C. The impact of biosensing in a pandemic outbreak: COVID-19. Biosens Bioelectron. 2020;163:112274. doi:10.1016/j.bios.2020.112274

156. COVID-19 $15 \mathrm{~min}$ RAPID POC test - Assay Genie; n.d. Available from: https://www.assaygenie.com/covid-19-15-minrapid-poc-test. Accessed September 26, 2020.

157. WHO; 2019. Available from: https:/www.who.int/news-room/ fact-sheets/detail/hiv-aidsAccessed September 26, 2020.

158. Cepheid | sars-cov-2-en-test; n.d. Available from: https://www. cepheid.com/en/about/SARS-CoV-2-Test-DevelopmentInformation. Accessed September 26, 2020.

159. COVID-19 - atilaBiosystems; n.d. Available from: https://atilabio systems.com/our-products/covid-19/. Accessed September 26, 2020.

160. Döhla M, Boesecke C, Schulte B, et al. Rapid point-of-care testing for SARS-CoV-2 in a community screening setting shows low sensitivity. Public Health. 2020;182:170. doi:10.1016/j.puhe.2020.04.009
International Journal of Nanomedicine

\section{Publish your work in this journal}

The International Journal of Nanomedicine is an international, peerreviewed journal focusing on the application of nanotechnology in diagnostics, therapeutics, and drug delivery systems throughout the biomedical field. This journal is indexed on PubMed Central, MedLine, CAS, SciSearch ${ }^{\mathbb{R}}$, Current Contents ${ }^{\mathbb{B}} /$ Clinical Medicine,
Journal Citation Reports/Science Edition, EMBase, Scopus and the Elsevier Bibliographic databases. The manuscript management system is completely online and includes a very quick and fair peer-review system, which is all easy to use. Visit http://www.dovepress.com/ testimonials.php to read real quotes from published authors. 